\title{
A cation counterflux supports lysosomal acidification
}

\author{
Benjamin E. Steinberg, ${ }^{1,2}$ Kassidy K. Huynh, ${ }^{1,3}$ Alexandre Brodovitch, ${ }^{1}$ Sabrina Jabs, ${ }^{4}$ Tobias Stauber, ${ }^{4}$ \\ Thomas J. Jentsch, ${ }^{4}$ and Sergio Grinstein ${ }^{1,2,3}$ \\ 'Program in Cell Biology, Hospital for Sick Children, Toronto, Canada M5G 1 X8 \\ ${ }^{2}$ Institute of Medical Science and ${ }^{3}$ Department of Biochemistry, University of Toronto, Ontario, Canada M5S 1A8 \\ ${ }^{4}$ Leibniz-Institut für Molekulare Pharmakologie (FMP) and Max-Delbrück-Centrum für Molekulare Medizin (MDC), D-13125 Berlin, Germany
}

$\mathrm{T}$ he profound luminal acidification essential for the degradative function of lysosomes requires a counter-ion flux to dissipate an opposing voltage that would prohibit proton accumulation. It has generally been assumed that a parallel anion influx is the main or only counter-ion transport that enables acidification. Indeed, defective anion conductance has been suggested as the mechanism underlying attenuated lysosome acidification in cells deficient in CFTR or ClC-7. To assess the individual contribution of counter-ions to acidification, we devised means of reversibly and separately permeabilizing the plasma and lysosomal mem- branes to dialyze the cytosol and lysosome lumen in intact cells, while ratiometrically monitoring lysosomal $\mathrm{pH}$. Replacement of cytosolic $\mathrm{Cl}^{-}$with impermeant anions did not significantly alter proton pumping, while the presence of permeant cations in the lysosomal lumen supported acidification. Accordingly, the lysosomes were found to acidify to the same $\mathrm{pH}$ in both CFTR- and ClC-7-deficient cells. We conclude that cations, in addition to chloride, can support lysosomal acidification and defects in lysosomal anion conductance cannot explain the impaired microbicidal capacity of CF phagocytes.

\section{Introduction}

Lysosomes are the terminal compartment of the endocytic pathway. Their various acid hydrolases endow the organelle with the degradative capacity necessary to break down proteins, lipids, and polysaccharides. In certain cells, such as macrophages, lysosomes assume additional, specialized functions. Macrophages are important components of the innate immune response as they engage, internalize, and destroy invading microorganisms. In addition to homeostatic degradative functions, their lysosomes contribute antimicrobial capacities by fusing with the intracellular vacuole that ensnares the internalized pathogen. Most lysosomal hydrolases are optimally active in highly acidic solutions (Pillay et al., 2002), which mandates that the organellar lumen be maintained at $\mathrm{pH}$ values between 4 and 5. In macrophages, proton transport into phago-lysosomes also favors bacterial clearance by supporting NADPH oxidase activity, promoting the

Correspondence to Sergio Grinstein: sga@sickkids.ca

Abbreviations used in this paper: bzATP, $2^{\prime},\left(3^{\prime}\right)$-O-(4-benzoylbenzoyl)adenosine5'-triphosphate; CcA, concanamycin A; CF, cystic fibrosis; CFTR, cystic fibrosis transmembrane conductance regulator; FCCP, carbonyl cyanide 4-(trifluoromethoxy)phenylhydrazone; GPN, glycyl-phenylalanine- $\beta$-naphthylamide; MES, 2-(N-morpholino)ethanesulfonic acid; $\mathrm{MeSO}_{3}$, methanesulfonate; $\mathrm{NMDG}^{+}$, $\mathrm{N}$-methyl-D-glucammonium; TMA, trimethylamine; Tris, tris(hydroxymethyl)aminomethane; V-ATPase, vacuolar-type ATPase. generation of toxic oxygen radicals and enhancing the activity of cationic microbicidal peptides. By regulating protease activity, the $\mathrm{pH}$ further controls antigen presentation and subsequent adaptive immune responses.

The pronounced acidification of the lysosomal interior is generated by the vacuolar-type ATPase (V-ATPase), a multimeric enzyme complex that utilizes the energy of ATP hydrolysis to translocate protons across membranes (Forgac, 2007). While the catalytic cycle of the V-ATPase drives proton accumulation, other factors contribute to the establishment of lysosomal acidification. The vectorial movement of protons across the membrane generates a transmembrane electrical potential difference (positive inside) that, if left uncompensated, curtails the activity of the $\mathrm{V}$-ATPase and limits the magnitude of the $\mathrm{pH}$ gradient. To circumvent this self-limiting behavior, counter-ion conductive pathways must operate alongside the V-ATPase to dissipate the mounting voltage. Either the influx of cytosolic anions into the

(C) 2010 Steinberg et al. This article is distributed under the terms of an AttributionNoncommercial-Share Alike-No Mirror Sites license for the first six months after the publication date (see http://www.rupress.org/terms). After six months it is available under a Creative Commons License (Attribution-Noncommercial-Share Alike 3.0 Unported license, as described at http://creativecommons.org/licenses/by-nc-sa/3.0/). 
organelle or the efflux of luminal cations can in principle serve as an electrical shunt to facilitate acidification.

Despite their importance to lysosomal acidification, the identity of the neutralizing counter-ions and their conductive channels in lysosomes remains elusive. Studies using pharmacological approaches alongside organellar $\mathrm{pH}$ measurements have largely focused on endosomes, and have implicated chloride as the principal counter-ion that dissipates the endosomal membrane potential generated by the V-ATPase. The intracellular CLC chloride channel family members ClC-3, ClC-4, and $\mathrm{ClC}-5$ have been proposed as the primary endosomal chloride conductance providers (Günther et al., 1998, 2003; Piwon et al., 2000; Li et al., 2002; Mohammad-Panah et al., 2003; HaraChikuma et al., 2005a,b). ClC-7 is expressed in late endosomes and lysosomes (Kornak et al., 2001), but there is disagreement in the literature regarding its contribution to acidification (Kornak et al., 2001; Kasper et al., 2005; Lange et al., 2006; Graves et al., 2008). More recently, the cystic fibrosis (CF) transmembrane conductance regulator chloride channel (CFTR) was proposed as the specific counter-ion conductance necessary for lysosomal acidification in alveolar macrophages (Di et al., 2006). The lysosomes of CFTR-deficient macrophages were found to remain near neutrality, decreasing the capacity of these cells to clear a bacterial challenge (Di et al., 2006). The lung disease seen in CF was accordingly suggested to result in part from impaired lysosomal function. This mechanistic interpretation of CF pathobiology, however, has since been challenged (Haggie and Verkman, 2007; Lamothe and Valvano, 2008; Barriere et al., 2009).

Because of their central role in lysosome biology and potential involvement in the pathogenesis of $\mathrm{CF}$, we analyzed the counter-ion pathways that support lysosomal acidification in macrophages using novel approaches to manipulate the ionic composition of the cytosol and of the lysosomal lumen in macrophages.

\section{Results}

The role of CFTR in Iysosomal acidification To investigate the counter-ions that support acidification, the lysosomes of murine macrophages were loaded with $\mathrm{pH}$-sensitive dextrans and subjected to ratiometric imaging (Fig. 1, A and B). In the RAW264.7 and J774 macrophage lines, the steady-state lysosomal $\mathrm{pH}$ was $4.71 \pm 0.04$ and $4.52 \pm 0.06$, respectively (all values listed as mean $\pm \mathrm{SE}$; Fig. $1 \mathrm{C}$ ). As expected, lysosomal acidification was dissipated by concanamycin A (CcA), an inhibitor of the V-ATPase ( $\mathrm{pH} \geq 6.5$, the upper limit of $\mathrm{pH}$ sensitivity of our sensor; Fig. 1, B and C). To evaluate its role in maintaining baseline $\mathrm{pH}$, CFTR was pharmacologically inhibited by treating the cells for $1 \mathrm{~h}$ with the specific inhibitor CFTR $_{\mathrm{INH}^{-}}$172, which has been validated in multiple systems (Ma et al., 2002; Thiagarajah et al., 2004; Perez et al., 2007). No perturbation in steady-state lysosomal $\mathrm{pH}$ was observed in either cell line after treatment with the inhibitor $(\mathrm{pH}=4.77 \pm$ 0.06 and $4.51 \pm 0.05$ for RAW264.7 and J774 cells, respectively, at $5 \mu \mathrm{M} \mathrm{CFTR} \mathrm{INH}^{-172}$ and $4.82 \pm 0.08$ and $4.75 \pm 0.11$ at $10 \mu \mathrm{M}$; Fig. $1 \mathrm{C}$ ). Of note, the concentrations of $\mathrm{CFTR}_{\mathrm{INH}^{-}} 172$ used are much greater than those required for full inhibition of CFTR ( $\mathrm{IC}_{50} \approx 300 \mathrm{nM}$; Ma et al., 2002).

In the study by Di et al. (2006), CFTR was implicated in modulating lysosomal $\mathrm{pH}$ specifically in alveolar, but not other types of macrophages. To confirm this result, primary murine alveolar macrophages harvested by bronchoalveolar lavage were used to measure lysosomal $\mathrm{pH}$. The steady-state $\mathrm{pH}$ (4.64 \pm 0.02 ) was not significantly altered by incubation with $10 \mu \mathrm{M}$ CFTR $_{\mathrm{INH}^{-}}-172$ (4.75 \pm 0.03 ; Fig. $\left.1 \mathrm{D}\right)$. That CFTR does not contribute importantly to lysosomal acidification was corroborated comparing alveolar macrophages from wild-type and CFTRdeficient mice. The lysosomal $\mathrm{pH}$ was virtually identical in wild-type and $c f t r^{-/}$macrophages $(4.64 \pm 0.02$ and $4.58 \pm$ 0.06 , respectively), and CcA fully dissipated acidification in both cases (Fig. 1 D). These observations rule out the possibility that residual CFTR activity, due to incomplete inhibition by $\mathrm{CFTR}_{\mathrm{INH}^{-}}-172$, provided the counter-ion conductance for lysosomal acidification.

Pharmacological inhibition of the V-ATPase with CcA unmasks a proton leak that gradually dissipates lysosomal acidification. Because net proton leakage requires translocation of a counter-ion, the rate of $\mathrm{pH}$ change caused by $\mathrm{CcA}$ can also be used to assess CFTR-mediated conductance in lysosomes. As shown in Fig. $1 \mathrm{E}$, the initial rates of lysosomal alkalinization in alveolar macrophages harvested from wild-type and $\mathrm{cftr}^{-/-}$ mice were not significantly different $\left(0.20 \pm 0.01 \mathrm{~min}^{-1}\right.$ and $0.16 \pm 0.02 \mathrm{~min}^{-1}$, respectively; $\left.\mathrm{P}=0.28\right)$, confirming that CFTR is not the predominant conductive pathway of the lysosomal membrane.

Role of CIC-7 in Iysosomal acidification Another $\mathrm{Cl}^{-}$conductance, the rheogenic $2 \mathrm{Cl}^{-} / \mathrm{H}^{+}$antiporter $\mathrm{ClC}-7$, has also been discussed in lysosomal acidification (Kornak et al., 2001; Graves et al., 2008). As shown in Fig. 2, A and B, ClC-7 is expressed in both RAW264.7 cells and in primary alveolar macrophages, where it colocalizes with the lysosomal marker LAMP-1 (Fig. S1). To address the possible involvement of $\mathrm{ClC}-7$ in lysosome acidification, $\mathrm{pH}$ was measured in alveolar macrophages isolated from either wild-type or $\mathrm{ClC}-7$ knockout mice (Kornak et al., 2001). Immunofluorescence determinations (Fig. 2 B) verified the absence of ClC-7 in the macrophages from knockout animals. As illustrated in Fig. $2 \mathrm{C}$, lysosomal $\mathrm{pH}$ in the macrophages of transporter-deficient $\mathrm{Clcn}^{-1-}$ animals $(4.73 \pm$ 0.12 ) was not significantly different from that in littermate controls $(4.72 \pm 0.24)$, in agreement with earlier ratiometric measurements of lysosomal $\mathrm{pH}$ in neurons and fibroblasts (Kasper et al., 2005; Lange et al., 2006). Fig. 2 C also shows that treatment of $C l c n 7^{-1-}$ macrophages with $\mathrm{CFTR}_{\mathrm{INH}^{-}} 172$ inhibitor was without effect on baseline lysosome $\mathrm{pH}(4.72 \pm 0.15)$, suggesting that anion conductance via CFTR does not become especially important in the absence of ClC-7.

\section{Role of cytosolic anions in}

Iysosonal acidification

Although we failed to implicate CFTR or $\mathrm{ClC}-7$ as the primary counter-ion conductance pathways, cytosolic anions, mainly $\mathrm{Cl}^{-}$, remained as leading candidates to provide the counter-charge for 

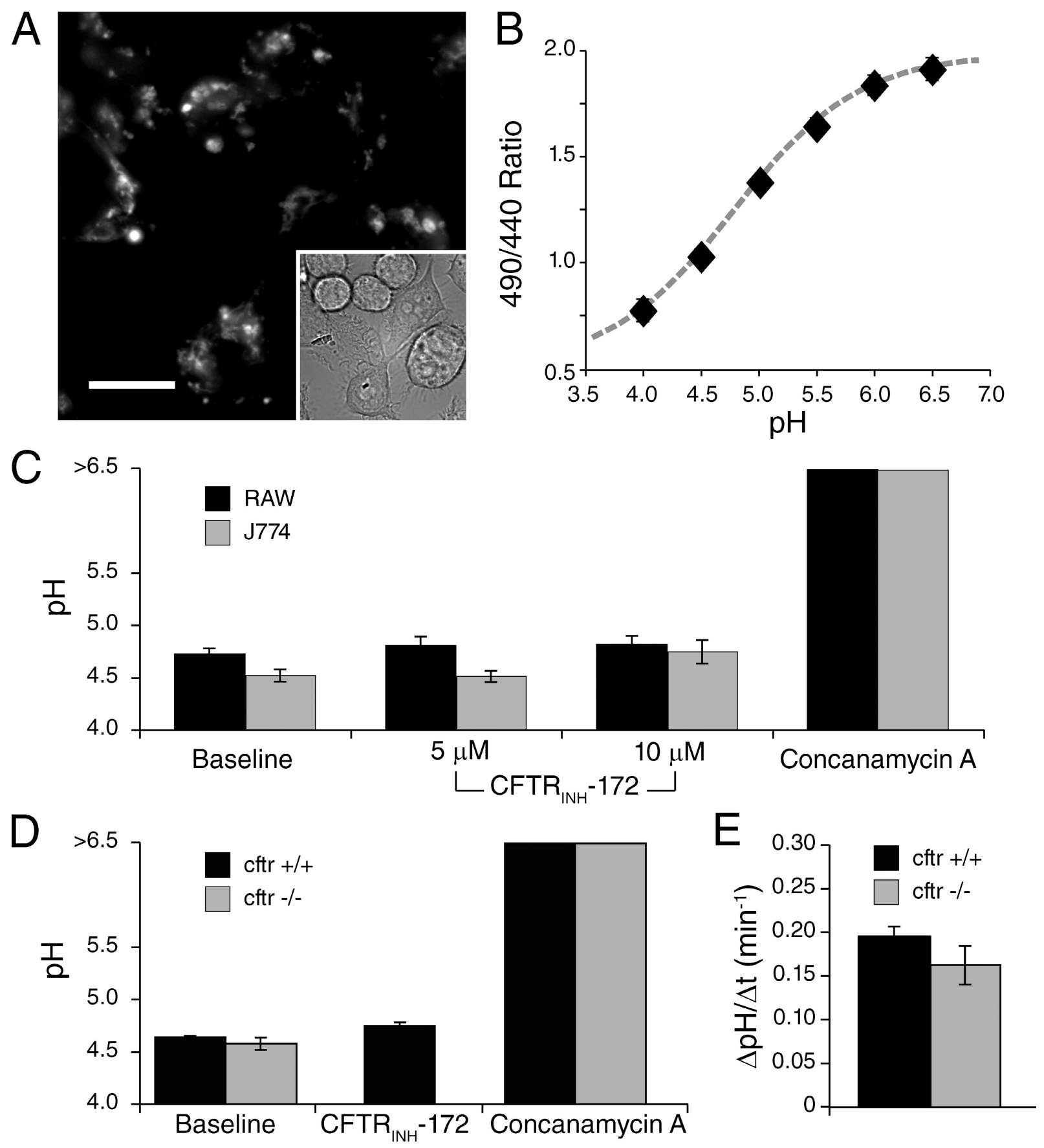

Figure 1. Steady-state lysosomal pH in macrophages. (A) The lysosomes of murine macrophages were loaded with $\mathrm{pH}$-sensitive dextrans and their $\mathrm{pH}$ measured by ratiometric imaging. A representative field of RAW264.7 macrophages is shown in A (bar, $10 \mu \mathrm{m})$ with the corresponding differential interference contrast (DIC) image in the inset. At the end of each experiment, an in situ calibration was performed as described in Materials and methods to generate a curve relating the $490 \mathrm{~nm} / 440 \mathrm{~nm}$ excitation ratio to $\mathrm{pH}$ (B). (C) The macrophage cell lines RAW264.7 (black bars) and J774 (gray bars) were either left untreated (5 experiments with a total of 669 lysosomes, and 5 experiments, 1103 lysosomes, respectively) or treated with $5 \mu M$ (3 experiments, 538 lysosomes; and 4 experiments, 810 lysosomes, respectively) or $10 \mu \mathrm{M}(3$ experiments, 304 lysosomes; and 4 experiments, 861 lysosomes, respectively) of the CFTR inhibitor CFTR $\mathbb{I N H}_{-172}$ for $1 \mathrm{~h}$, and the lysosomal $\mathrm{pH}$ was recorded. In both cell lines, treatment with $500 \mathrm{nM}$ CcA for $1 \mathrm{~h}$ dissipated the lysosomal pH to values greater than 6.5 , the upper limit of sensitivity of the $\mathrm{pH}$ probe. (D) Lysosomal $\mathrm{pH}$ in alveolar macrophages harvested from wild-type or $\mathrm{cfrr}^{-1-}$ mice $(5$ experiments, 509 lysosomes; and 5 experiments, 395 lysosomes, respectively). Wild-type cells were also incubated for $1 \mathrm{~h}$ in the presence of $10 \mu \mathrm{M}$ of CFTR $\mathbb{N H H}^{-172}$ (4 experiments, 450 lysosomes). (E) To determine whether CFTR functions as the counter-ion conductance for the proton leak in lysosomes, wild-type (3 experiments, 24 lysosomes) and $\mathrm{cftr}^{-1-}$ (4 experiments, 34 lysosomes) alveolar macrophages were treated with $1 \mu \mathrm{M} \mathrm{CcA}$ and the rate of alkalinization was measured over the first $5 \mathrm{~min}$.

proton uptake by lysosomes. To validate this notion we used a cytosolic ion-substitution protocol in combination with lysosomal pH measurements, as depicted schematically in Fig. 3 A. In brief, the plasma membrane of RAW macrophages was selectively permeabilized by stimulating resident $\mathrm{P} 2 \mathrm{X}_{7}$ receptors with the agonist $2^{\prime},\left(3^{\prime}\right)$ - $O$-(4-benzoylbenzoyl)adenosine-5'-triphosphate (bzATP), a process validated earlier in this cell line by Pelegrin et al. (2008). Upon activation, $\mathrm{P} 2 \mathrm{X}_{7}$ receptors form large pores 
Figure 2. Expression of ClC-7 in alveolar macrophages: role in the establishment of lysosomal $\mathrm{pH}$. (A) The expression of $\mathrm{ClC}-7$ in membranes isolated from fibroblasts of wild-type (WT) and ClC-7 knockout (KO) mice and in RAW264.7 macrophages was tested by immunoblotting, using the antibody described in Kornak et al. (2001). To verify comparable loading, the blots were also probed for the Golgi protein GM130 and for actin. (B) Alveolar macrophages obtained from wild-type $\left(\mathrm{Clcn}^{7^{+/+}}\right)$and $\mathrm{ClC}$-7 knockout mice $\left(\mathrm{Clcn}^{-1-}\right)$ were immunostained for $\mathrm{ClC}-7$ (middle column; green in right column) and for the macrophage marker F4/80 (red in right column), and their nuclei stained with Hoechst 33342 (blue). Corresponding bright-field images are shown in the left column. Bar, $10 \mu \mathrm{m}$. (C) Lysosomal $\mathrm{pH}$ in alveolar macrophages harvested from wild-type (black bars) or $\mathrm{Clcn}^{-1}$ mice without or with $10 \mu \mathrm{M} \mathrm{CFTR} \mathbb{N N H}^{-172}$ (gray and white bars, respectively). Four experiments were performed per mouse type. For each experiment, at least 10 cells (each with $\geq 10$ lysosomes) were measured.
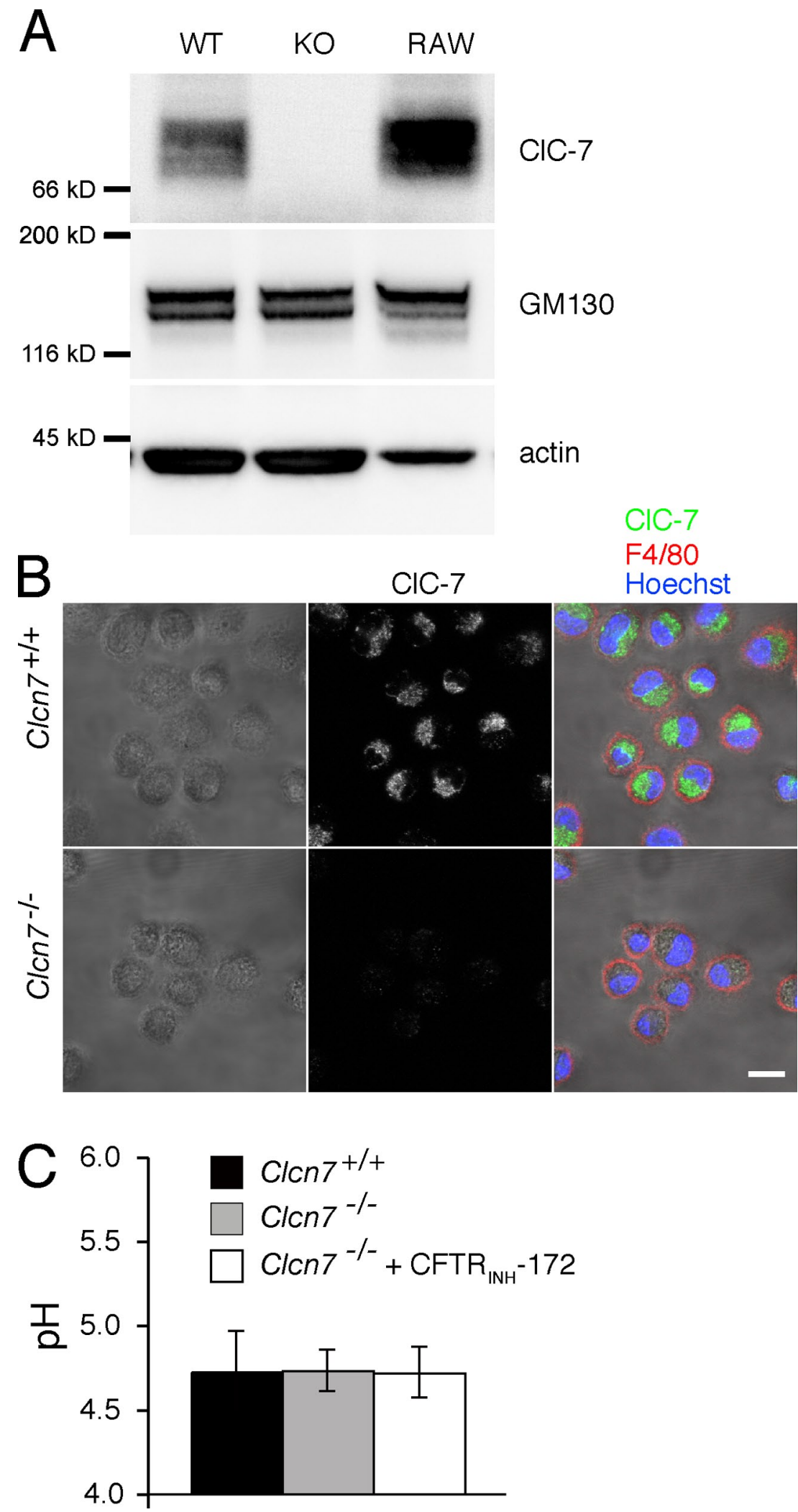

through which molecules $\mathrm{M}_{\mathrm{r}} \leq 900 \mathrm{D}$ are able to pass (Pelegrin and Surprenant, 2006). The well-defined, limited size of the $\mathrm{P} 2 \mathrm{X}_{7}$ mediated-pores and the fact that they close rapidly upon addition of divalent cations makes this an elegant and conservative means of manipulating the cytosolic ion content. By stimulating $\mathrm{P} 2 \mathrm{X}_{7}$ receptors while the cells are bathed in media where $\mathrm{Cl}^{-}$is replaced by organic anions such as gluconate or methanesulfonate $\left(\mathrm{MeSO}_{3}{ }^{-}\right)$, the cytosolic $\mathrm{Cl}^{-}$can be dialyzed in exchange for the larger anions. Colorimetric $\mathrm{Cl}^{-}$determinations demonstrated that the total intracellular $\mathrm{Cl}^{-}$content decreased from $70.5 \pm 4.2 \mathrm{mM}$ 

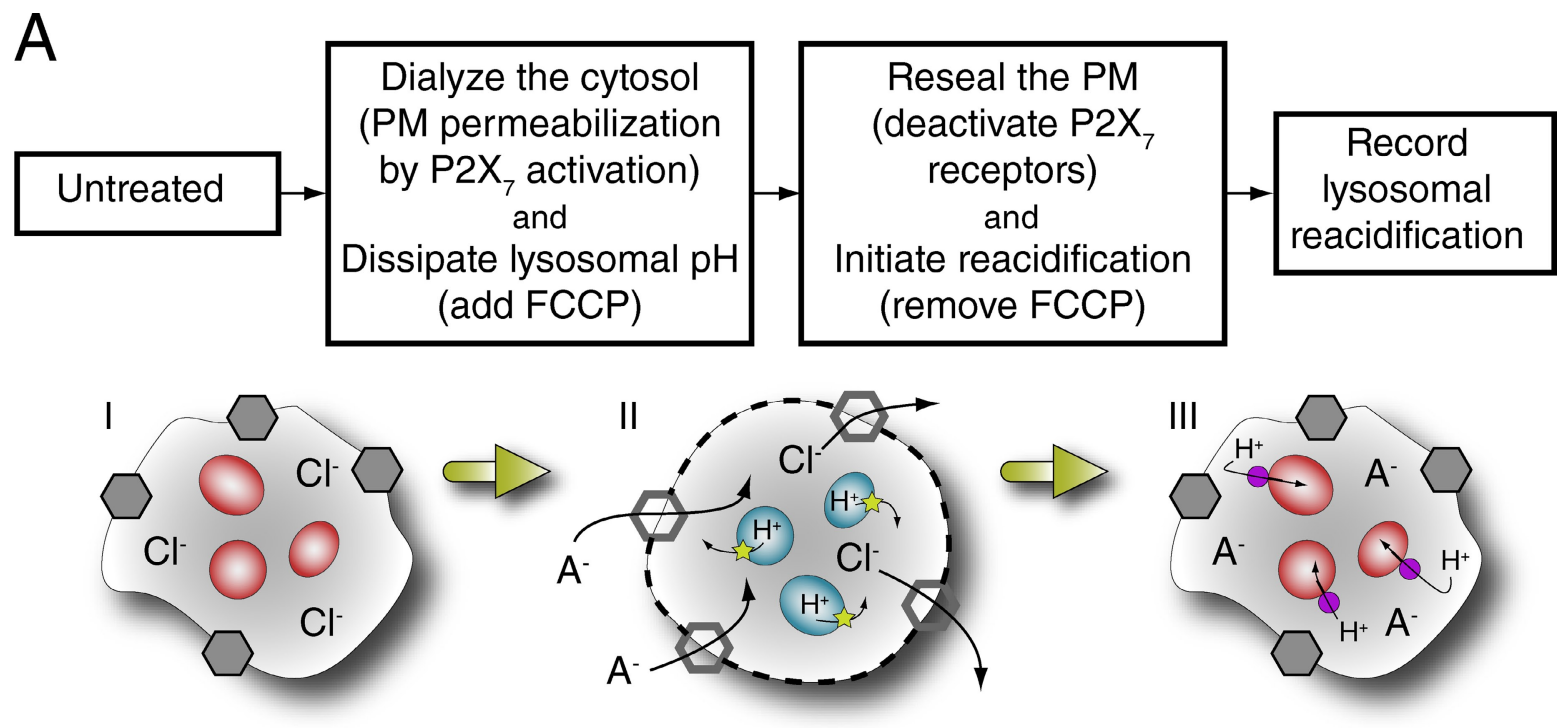

B
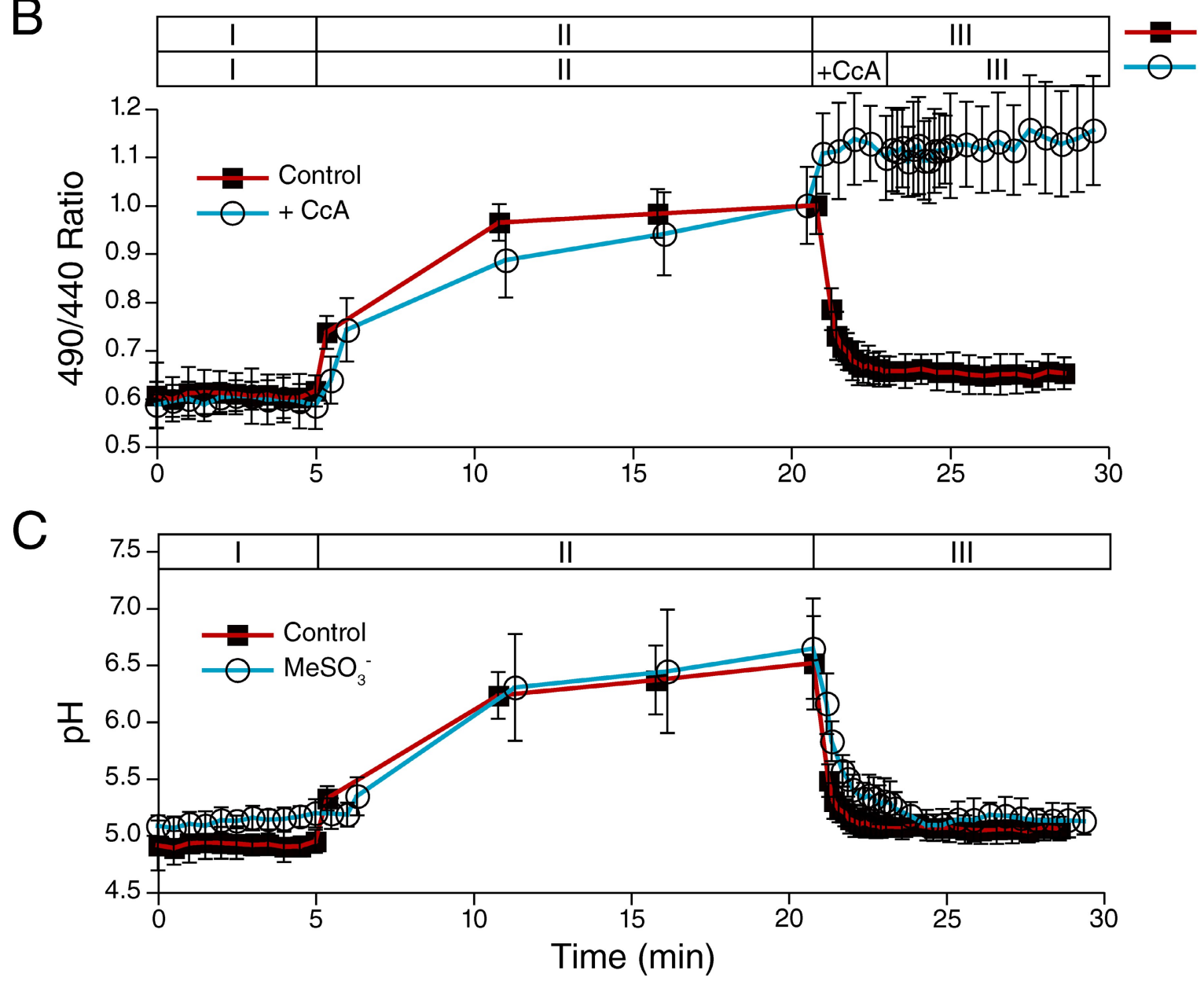

Figure 3. Role of cytosolic anions in lysosome re-acidification after protonophore-induced alkalinization. (A) Schematic representation of the experimental protocol used to dialyze cytosolic anions and transiently alkalinize lysosomes. After baseline pH measurements in RAW macrophages (step I), the cytosol was dialyzed by selectively permeabilizing the plasma membrane through the activation of $\mathrm{P} 2 \mathrm{X}_{7}$ receptors in the presence of anion substitution buffers (step II). Concurrently, the lysosomal pH was dissipated by treatment with the protonophore FCCP (step II). The plasma membrane was then resealed by removing the P2X, agonists and adding divalent cations, while lysosomal re-acidification was initiated by protonophore washout (step III). Lysosomal pH was monitored throughout the protocol. (B) Cells were subjected to the experimental protocol described in (A) while measuring $\mathrm{pH}$. Representative recordings of the fluorescence ratio (proportional to $\mathrm{pH}$ ) of untreated (filled squares) and CcA-treated cells (open circles) are illustrated (means $\pm \mathrm{SD}$ of $n=6$ and 9, respectively). The stages identified by the Roman numerals correspond to those in (A). Note that inhibition of the V-ATPase with CcA immediately before removal of FCCP fully abrogated lysosomal re-acidification. (C) Cytosolic anion substitution with $\mathrm{MeSO}_{3}{ }^{-}$did not change the rate or extent of lysosome re-acidification. Representative traces of control (filled squares) and anion-substituted (open circles) cells are shown (means \pm SD of $n=6$ ). Summary statistics are presented in Table I. 
Table I. Rate and extent of lysosome re-acidification after cytosolic anion dialysis and protonophore-induced alkalinization

\begin{tabular}{|c|c|c|c|c|}
\hline & $n$ & $\tau(\min )$ & $\mathrm{pH}_{\mathrm{f}}-\mathrm{pH}_{\mathrm{o}}$ & $\mathrm{pH}_{\mathrm{alk}}-\mathrm{pH}_{\mathrm{f}}$ \\
\hline Control & 16 & $0.68 \pm 0.07$ & $-0.01 \pm 0.03$ & $0.91 \pm 0.09$ \\
\hline Gluconate $^{-}$ & 6 & $\begin{array}{c}0.44 \pm 0.02 \\
(P>0.05 ; N S)\end{array}$ & $\begin{array}{l}-0.03 \pm 0.03 \\
(P>0.05 ; N S)\end{array}$ & $\begin{array}{c}0.72 \pm 0.17 \\
(P>0.05 ; N S)\end{array}$ \\
\hline $\mathrm{MeSO}_{4}^{-}$ & 6 & $\begin{array}{c}0.69 \pm 0.06 \\
(P>0.05 ; N S)\end{array}$ & $\begin{array}{r}0.09 \pm 0.05 \\
(P>0.05 ; N S)\end{array}$ & $\begin{array}{c}1.31 \pm 0.05 \\
(P<0.05)\end{array}$ \\
\hline $\mathrm{CFTR}_{\mathbb{N N H}^{-1}} 172$ & 5 & $\begin{array}{c}1.34 \pm 0.25 \\
(P<0.01)\end{array}$ & $\begin{array}{l}-0.17 \pm 0.10 \\
(P>0.05 ; N S)\end{array}$ & $\begin{array}{c}0.71 \pm 0.07 \\
(P>0.05 ; N S)\end{array}$ \\
\hline
\end{tabular}

The differences between the initial lysosome $\mathrm{pH}\left(\mathrm{pH}_{0}\right.$; step I of the protocol shown in Fig. $\left.3 \mathrm{~A}\right)$, $\mathrm{pH}$ after protonophore-induced alkalinization ( $\mathrm{pH}$ alki step II of the protocol in Fig. $3 \mathrm{~A})$, and final $\mathrm{pH}$ after re-acidification $\left(\mathrm{pH}_{\mathrm{f}}\right.$; step III of the protocol in Fig. $\left.3 \mathrm{~A}\right)$ were calculated. To determine the half-life of the $\mathrm{pH}$ decay $(\tau)$ the data for lysosome re-acidification after protonophore washout were fit to a single exponential of the form $y=A$ * $\exp (-K x)+B$ and $\tau$ calculated as $0.69 / K$. All values are listed as mean $\pm \mathrm{SE}$. The p-values, given in parentheses, were determined by ANOVA using Dunnett's test for multiple comparison to the control (NS, not significant). $n$ refers to the number of experiments performed for each condition. For each experiment, 6-13 regions of interest were measured.

to $8.5 \pm 1.7 \mathrm{mM}$ after $15 \mathrm{~min}$ of bzATP treatment in media devoid of $\mathrm{Cl}^{-}$(Fig. S2, A and B). The remaining $\mathrm{Cl}^{-}$reflects a pool of slowly exchangeable or nonexchangeable organellar $\mathrm{Cl}^{-}$. This was concluded from determinations of $\mathrm{Cl}^{-}$released by bzATP into the medium, which is maximal in the first $5 \mathrm{~min}$ and negligible after $15 \mathrm{~min}$

To optimize detection of V-ATPase-induced acidification, the lysosomes were transiently alkalinized using the protonophore carbonyl cyanide 4-(trifluoromethoxy)phenylhydrazone (FCCP) concurrently with the cytosolic dialysis step. Re-acidification was then initiated by removal of the protonophore, which was effected concomitantly with the closure of $\mathrm{P} 2 \mathrm{X}_{7}$-induced pores. When the dialysis medium contained $50 \mathrm{mM} \mathrm{Cl}^{-}$to mimic the normal $\mathrm{Cl}^{-}$content of the cytosol, lysosomes rapidly re-acidified to baseline values after plasma membrane resealing and protonophore washout (Fig. 3 B). Notably, the re-acidification was inhibited by addition of CcA immediately before protonophore washout (Fig. 3 B), verifying that the drop in $\mathrm{pH}$ is due to the activity of the V-ATPase. Consistent with our previous results, treatment with $10 \mu \mathrm{M} \mathrm{CFTR} \mathrm{INH}^{-172}$ did not alter the extent of re-acidification, though the rate was reduced by $\sim 50 \%$ (Table I). The mechanism underlying the reduction in rate is unclear; although it may reflect a contribution of CFTR to the counter-ion conductance, we regard this possibility as unlikely in view of the earlier results obtained using $c f t r^{-/}$mice. CFTR $_{\mathrm{INH}^{-}} 172$ may be blocking other counter-ion pathways or inducing a proton leak that partially offsets the rate of acidification. More importantly, replacement of cytosolic $\mathrm{Cl}^{-}$with either $\mathrm{MeSO}_{3}{ }^{-}$ (Fig. 3 C) or gluconate (unpublished data) had no discernible effect on either the rate or extent of re-acidification (Table I). It follows that $\mathrm{Cl}^{-}$and other small cytosolic anions are not absolutely necessary for lysosome acidification. As both $\mathrm{MeSO}_{3}{ }^{-}$ and gluconate are poorly permeable through CFTR (Linsdell et al., 1997), these data lend further evidence against CFTR as the counter-ion conductance.

Although our determinations indicate that during the ionsubstitution studies minimal $\mathrm{Cl}^{-}$remained in the cytosol after dialysis, it is possible that a small amount of residual $\mathrm{Cl}^{-}$contributed to the rapid re-acidification kinetics. To address this possibility, we performed in vitro experiments measuring the $\mathrm{pH}$ of isolated lysosomes in a cell-free system. To this end, the lysosomes of RAW macrophages were first labeled with dextran conjugated to a fluorescent $\mathrm{pH}$ sensor, using a pulse-chase loading protocol.
Selective labeling of the lysosomes obviated the need for extensive purification of these organelles, which is time consuming and can result in swelling and alteration of permeability properties. The $\mathrm{pH}$ gradient across the lysosomal membrane was then dissipated by treatment with the protonophore FCCP, the cells were homogenized, and the endomembrane compartments isolated through centrifugation. During protonophore treatment and organelle isolation the cells and homogenate were maintained either in $\mathrm{Cl}^{-}$-containing medium or in a medium where all $\mathrm{Cl}^{-}$was substituted by gluconate. The $\mathrm{pH}$ of the isolated lysosomes was monitored in the corresponding solution using a fluorescence spectrometer. After a baseline measurement, ATP and Mg were added to the endomembrane suspension to activate the V-ATPase and initiate acidification, while continually monitoring fluorescence. As shown in Fig. 4 A, when maintained in the presence of $\mathrm{Cl}^{-}$the isolated lysosomes retained the ability to re-acidify, as indicated by quenching of the fluorescence. Subsequent addition of the $\mathrm{K}^{+} / \mathrm{H}^{+}$exchanger nigericin restored the original fluorescence, implying that the lysosomes remained intact and suggesting that ATP-Mg had indeed altered the luminal pH. Accordingly, when added in the presence of CcA, ATP-Mg failed to induce the acute acidification noted above (Fig. 4 B). Most notably, lysosomes that were isolated and maintained in medium devoid of $\mathrm{Cl}^{-}$were similarly capable of acidifying and this response was equally sensitive to CcA, implying mediation by the V-ATPase (Fig. 4 B). Together, these observations confirm our earlier conclusion that permeant anions are dispensable for lysosome acidification.

It is important to note that the lysosomal membrane does possess a considerable $\mathrm{Cl}^{-}$conductance that, while not absolutely required for acidification, can nevertheless support it. In agreement with earlier observations, the ability of $\mathrm{Cl}^{-}$to support proton translocation was revealed when comparing the re-acidification of isolated lysosomes suspended in a sucrose-based medium either devoid of all permeant ions or supplemented with $\mathrm{Cl}^{-}$. To minimize their contribution, luminal cations were depleted by incubating the intact macrophages in a $\mathrm{Na}^{+}$- and $\mathrm{K}^{+}$-free, $N$-methyl-D-glucammonium $\left(\mathrm{NMDG}^{+}\right)$-based medium for $1 \mathrm{~h}$ before isolating the lysosomes. Whether the lysosomes undergo shrinkage during the depletion protocol remains unclear; volume loss could be minimized by generation of proteolytic products or by slow uptake of $\mathrm{NMDG}^{+}$during the prolonged depletion period. When internal $\mathrm{Na}^{+}$and $\mathrm{K}^{+}$were depleted proton pumping by the V-ATPase could not be sustained when permeable anions 

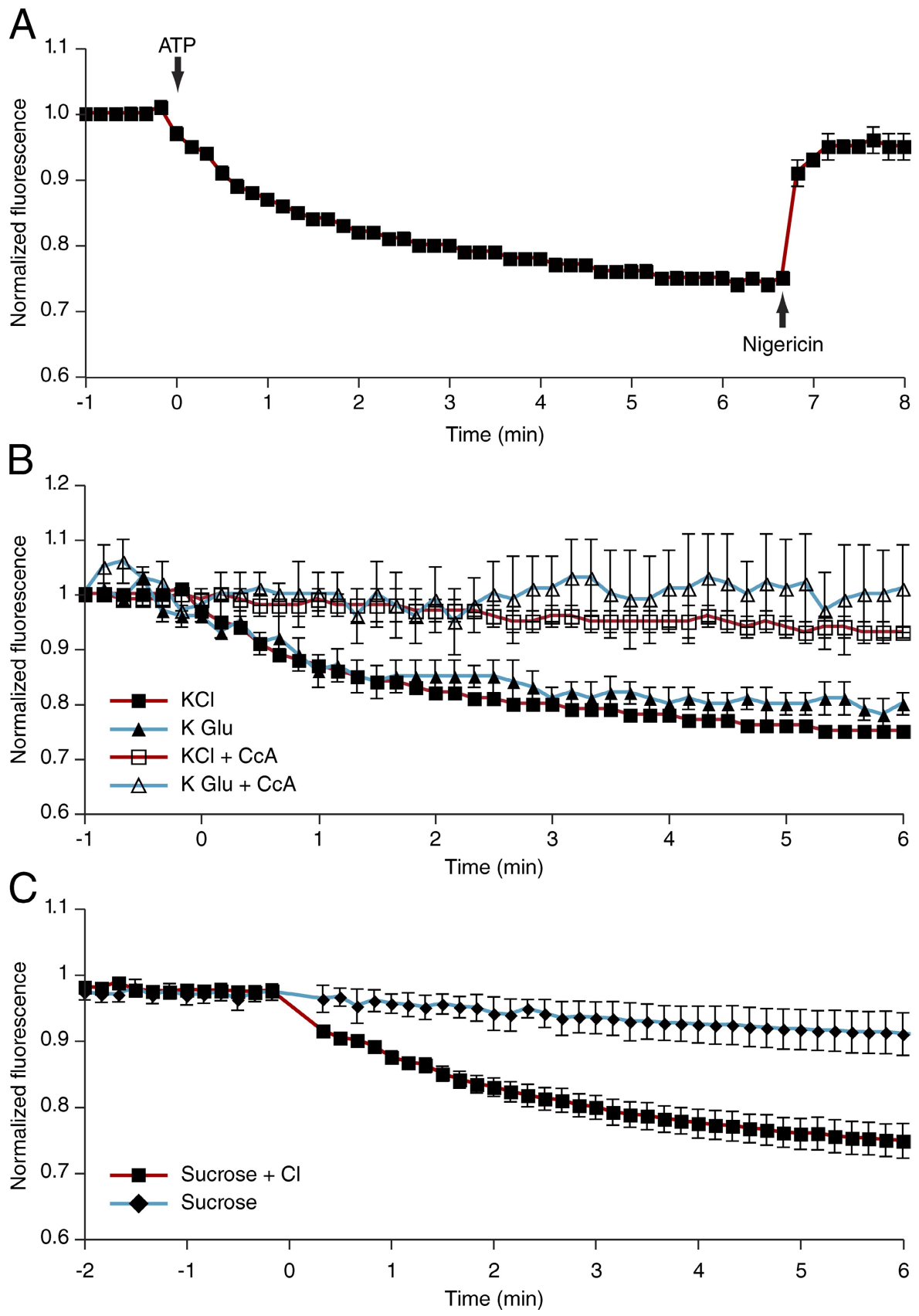

Figure 4. Role of anions in the acidification of isolated lysosomes. (A) The $\mathrm{pH}$ of isolated RAW macrophage lysosomes bathed in $\mathrm{Cl}^{-}$. containing medium was monitored by fluorescence spectrometry as described in the text. The $\mathrm{pH}$ gradient across the lysosomal membrane was intentionally dissipated during the course of isolation. Where indicated, lysosomal re-acidification was initiated by addition of ATP-Mg. Finally, nigericin was added to release the accumulated $\mathrm{H}^{+}$. (B) Isolated lysosomes were bathed in either $\mathrm{Cl}^{-}$-based (black squares) or gluconate-based (black triangles) medium and ATP-Mg was added as in A to initiate re-acidification. Where indicated, CcA was added concomitantly. Data are means \pm SE of at least three separate experiments of each kind. Lysosomes had undergone significant acidification at $5 \mathrm{~min}$ after the addition of MgATP as compared with CcA controls $\left(P=0.007\right.$ and $P=0.0159$ for the $\mathrm{Cl}^{-}$. and gluconate-based solutions, respectively). (C) Macrophages were incubated in medium devoid of small, monovalent cations (i.e., $\mathrm{K}^{+}$ and $\mathrm{Na}^{+}$) for $1 \mathrm{~h}$. The lysosomes were then isolated in either a sucrose-based medium or a sucrose-based medium containing $\mathrm{Cl}^{-}$. In both cases, the media were devoid of $\mathrm{K}^{+}$and $\mathrm{Na}^{+}$. Re-acidification was initiated as above by addition of ATP-Mg. Data are means \pm SE of at least three separate experiments of each kind for panels B and C. were omitted from the medium (Fig. 4 C), implying that any residual luminal cations were negligible contributors to the counter-ion flux. In the presence of $\mathrm{Cl}^{-}$, however, lysosomes were able to acidify upon the addition of $\operatorname{MgATP}$ (Fig. $4 \mathrm{C}$ ).

\section{Lysosomal $\mathrm{K}^{+}$and $\mathrm{Na}^{+}$determinations by null-point titration}

Because our evidence suggested that cytosolic anions are not absolutely required as counter-ions we considered whether luminal cations can also support lysosomal acidification. To date, the presence and in particular the concentration of free cations inside lysosomes has not been established, likely because the spectroscopic probes of cation activity are incompatible with the extreme acidity of the lysosomal lumen. Instead, we implemented a method that uses ionophores that exchange monovalent cations for protons with defined stoichiometry to indirectly assess cation activity. Based on the theoretical considerations summarized in the Materials and methods, the steady-state free concentration of $\mathrm{Na}^{+}$and $\mathrm{K}^{+}$can be estimated by means of a "null-point" titration of lysosomal $\mathrm{pH}$. This required manipulation of the cytosolic monovalent cation concentration, which was accomplished by reversible activation of plasmalemmal $\mathrm{P} 2 \mathrm{X}_{7}$ receptors, as described above, followed by graded alkalinization of the lysosomal lumen using the weak base trimethylamine (TMA). Three representative traces using different amounts of TMA for $\mathrm{K}^{+}$determination with nigericin are shown in Fig. 5 A. From multiple such determinations we estimated the null-point, i.e., the lysosomal $\mathrm{pH}$ at which $\Delta \mathrm{pH} / \Delta \mathrm{t}=0$ (Fig. $5 \mathrm{~B}$ ), which was in turn used to calculate $\mathrm{K}^{+}$activity as detailed in Materials and methods. From 15 independent determinations at 
Figure 5. Null-point titration determinations of lysosomal $\mathrm{K}^{+}$and $\mathrm{Na}^{+}$. Estimates of lysosomal $\mathrm{K}^{+}$and $\mathrm{Na}^{+}$in live RAW macrophages were obtained using the null-point method, as described in Materials and methods. Lysosomes were loaded with a $\mathrm{pH}$-sensitive dextran, and the cytosolic and extracellular compartments equilibrated using bzATP-activated $\mathrm{P}_{2} \mathrm{X}_{7}$ receptors. The lysosomes were alkalinized with the specified amount of TMA $(20 \mathrm{mM}$ or $15 \mathrm{mM}$ TMA added where indicated by the filled arrow, and $5 \mathrm{mM}$ TMA where indicated by the open arrow). Changes in lysosome $\mathrm{pH}$ upon the addition of a cation/proton exchanging ionophore were measured next to find the null-point, i.e., the condition when addition of the ionophore elicits no change in $\mathrm{pH}$. In the experiments shown in $A$, nigericin was added to all samples at $0 \mathrm{~min}$ (filled arrowhead). The traces are means \pm SD of three representative experiments. For each null-point titration experiment, the rate of $\mathrm{pH}$ change $(\Delta \mathrm{pH} / \Delta \mathrm{t})$ after addition of the ionophore was measured over $90 \mathrm{~s}$ and plotted as a function of the lysosome $\mathrm{pH}$ at the time of addition of the ionophore. The data obtained using nigericin and monen sin, used to estimate $\mathrm{K}^{+}$and $\mathrm{Na}^{+}$as detailed in Methods, are shown in B and $C$ along with the calculated least-squares linear regressions $\left(R^{2}=0.9272\right.$ and $R^{2}=0.7509$ for panels $B$ and $C$, respectively).

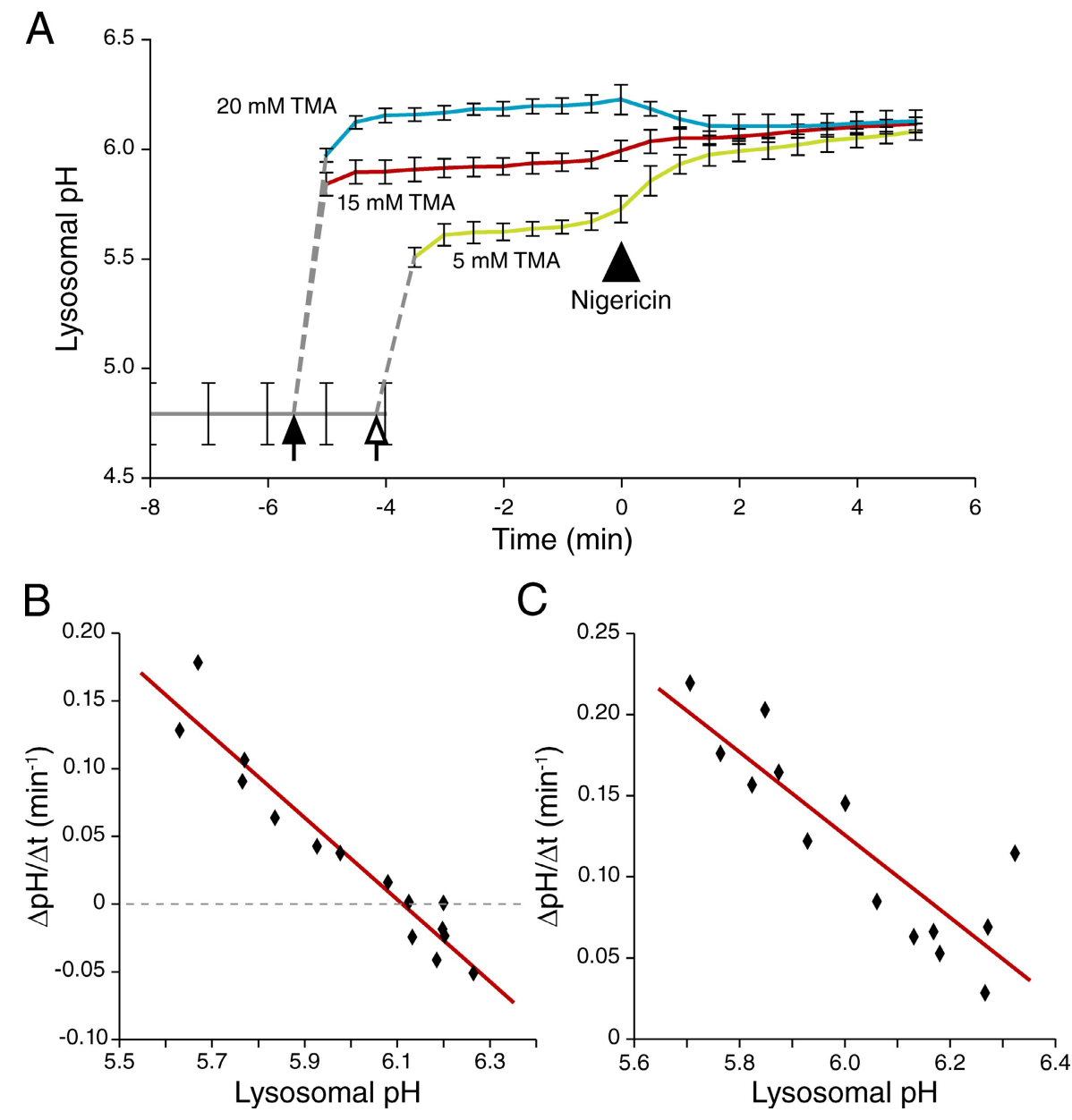

$\mathrm{pH}$ 6.5, each measuring between 6 and 8 lysosomes, we determined the free $\left[\mathrm{K}^{+}\right]$in the lumen of lysosomes to be $50.1 \pm$ $2.0 \mathrm{mM}$. To confirm the reliability of this determination we conducted a second null-point titration at pH 7.3 (Fig. S2 D). Elevating the cytosolic $\mathrm{pH}$ is expected to change the value of the null-point, but should nevertheless yield an estimate of the lysosomal $\mathrm{K}^{+}$content comparable to that calculated at $\mathrm{pH} 6.5$. Using the data obtained at cytosolic $\mathrm{pH} 7.3$ we calculated a null-point of $\mathrm{pH} 6.81 \pm 0.04$ corresponding to a luminal $\mathrm{K}^{+}$ content of $61.7 \pm 6.2 \mathrm{mM}$, in reasonable agreement with the value estimated at $\mathrm{pH} 6.5$.

Although nigericin is selective for $\mathrm{K}^{+} / \mathrm{H}^{+}$exchange, monensin, the ionophore used in the $\mathrm{Na}^{+}$null-point titration, is only moderately selective. It preferentially exchanges $\mathrm{Na}^{+}$for $\mathrm{H}^{+}$but is also capable of mediating $\mathrm{K}^{+} / \mathrm{H}^{+}$exchange with reduced efficiency. To calculate intra-lysosomal $\mathrm{Na}^{+}$activity the lysosomal $\left[\mathrm{K}^{+}\right]$, which was determined independently, and the selectivity coefficient of the ionophore were also taken into account (see Materials and methods). From monensin null-point titrations shown in Fig. $5 \mathrm{C}$, and using the lysosomal $\left[\mathrm{K}^{+}\right]$determined above, we estimate intra-lysosomal free $\left[\mathrm{Na}^{+}\right]$to be $20.6 \pm$ $2.1 \mathrm{mM}$. Considering the lysosomal buffering capacity $(61.5 \pm$ $2.3 \mathrm{mM} / \mathrm{pH}$ at $\mathrm{pH} 4.5-5 ; n=10$ experiments), it is clear that the aggregate content of monovalent cations is sufficient to support lysosomal acidification by over $1 \mathrm{pH}$ unit and/or its maintenance in the steady state.

\section{Role of luminal cations in}

Iysosomal acidification

To investigate whether luminal cations are capable of generating and maintaining lysosomal acidification, we used an ion-substitution strategy. Unlike the approach used to study anions, however, these experiments required manipulation of the internal cation content of the lysosomes. This was accomplished by transient permeabilization of the lysosomal membrane using the dipeptide Gly-Phe- $\beta$-naphthylamide (GPN), a compound previously used to dissipate and study the regulation of lysosomal $\mathrm{Ca}^{2+}$ (Berg et al., 1994; Haller et al., 1996a,b; Srinivas et al., 2002; McGuinness et al., 2007). This membrane-permeant reagent diffuses into lysosomes where it is cleaved by cathepsin $\mathrm{C}$, an exopeptidase found exclusively in these organelles (Jadot et al., 1984). The osmotically active products accumulate, drawing water into the lumen and leading to organelle swelling. When its ability to distend is exceeded, the lysosomal membrane undergoes a transient permeabilization. Under the conditions chosen for our experiments, the pore size generated by the permeabilization procedure is limited. Large molecules such as dextrans are retained by the lysosomes (Fig. 6 B), whereas smaller compounds like sulforhodamine $\left(M_{r}=607\right)$, and by extension small inorganic cations, are released (Fig. 6 A). As a result the $\mathrm{pH}$ of the lysosomal lumen equilibrates with that of the surrounding cytosol, and the lysosomes fail to accumulate LysoTracker (Fig. 6 C). Remarkably, after short (10 min) exposure periods to GPN, the permeabilization process can be 
A

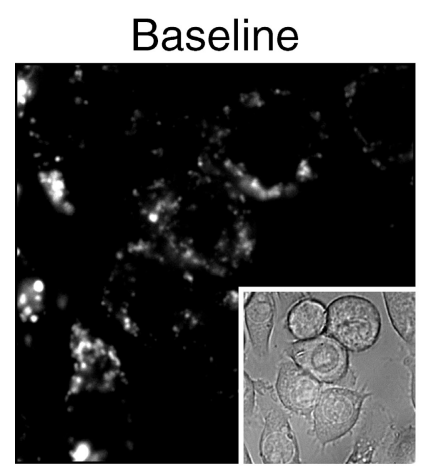

C

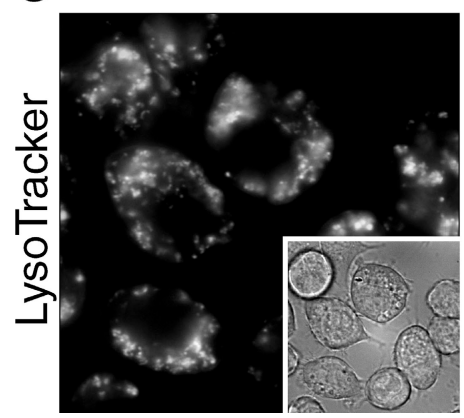

+ GPN

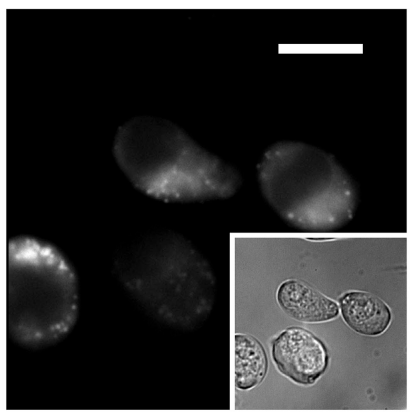

+ GPN

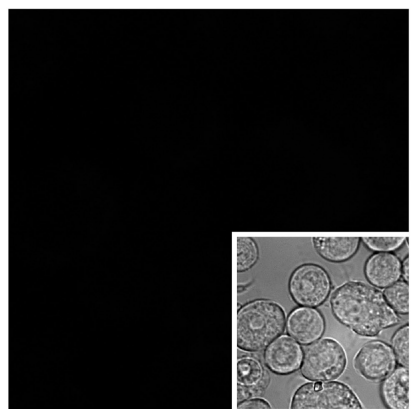

B

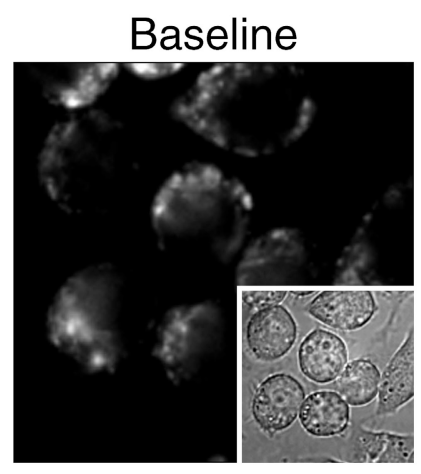

GPN washout

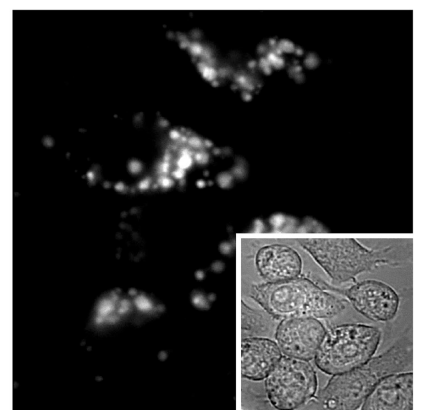

GPN washout $+\mathrm{CcA}$

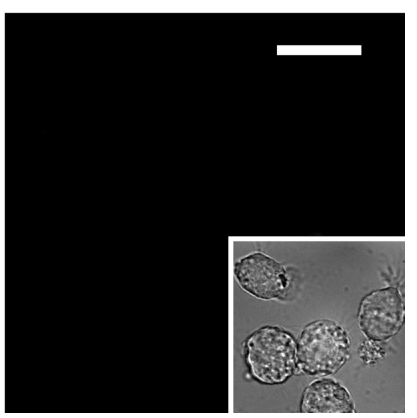

Figure 6. GPN-induced transient lysosome membrane permeabilization. Lysosomes of RAW264.7 macrophages were loaded with either (A) sulforhodamine or (B) fluorescently labeled dextrans (MW 10,000), and imaged before and after 10 min of GPN treatment. Corresponding DIC images are shown in the insets. (C) The $\mathrm{pH}$ of the lysosomes was monitored qualitatively using LysoTracker, which accumulates in acidic intracellular compartments. The dye was added to the cells either before GPN treatment, after 10 min of GPN treatment, or after 10 min of recovery subsequent to 10 min of GPN treatment. Dye accumulation was abrogated when CcA was added to the cells immediately after GPN washout. Representative fields (Bar, 10 mm) are shown along with their corresponding DIC images (insets).

reversed by removal of the dipeptide. Within minutes of GPN washout the lysosomes recover the ability to accumulate the acidotropic dye and the recovery is precluded by CcA (Fig. 6 C), implying that it reflects renewed proton pumping by the V-ATPase.

This transient permeabilization protocol enabled us to manipulate the ionic content of the lysosomal lumen to assess the role of monovalent cations in acidification. A schematic of the lysosome dialysis and alkalinization protocol is shown in Fig. 7 A. The baseline lysosomal $\mathrm{pH}$ was initially monitored in cells loaded with indicator probes (step I). The plasma membrane was then selectively permeabilized by $\mathrm{P}_{2} \mathrm{X}_{7}$ activation and the cytosol dialyzed while bathing the cells in either a cytosol-like ( $\mathrm{K}^{+}$-rich control) or cation-substituted medium (step II). To gain insight into the kinetics of cytosolic cation dialysis, $\mathrm{K}^{+}$was monitored using the fluorescent $\mathrm{K}^{+}$probe PBFI. When $\mathrm{P}_{2} \mathrm{X}_{7}$ receptors were stimulated in a $\mathrm{K}^{+}$-rich solution, no change in $\mathrm{K}^{+}$content was observed. In contrast, when the cells were bathed in an $\mathrm{NMDG}^{+}$-rich solution during $\mathrm{P}_{2} \mathrm{X}_{7}$ activation, intracellular $\mathrm{K}^{+}$was rapidly depleted within 10 min of dialysis (see Fig. S2 C). Accordingly, the cytosol dialysis (step II) was performed for $15 \mathrm{~min}$. After cytosolic dialysis the plasma membrane was resealed by deactivating the $\mathrm{P}_{2} \mathrm{X}_{7}$ receptors and the cells allowed 5 min to recover (step III). For the remainder of the experiment, the cells were bathed in the same medium used for cytosolic dialysis, except that the
$\mathrm{P} 2 \mathrm{X}_{7}$ agonist was removed and divalent cations were re-added. The lysosomes were next dialyzed (and inevitably alkalinized) by treatment with GPN (step IV). Finally, GPN was removed and the ability of lysosomes to re-acidify was monitored after $10 \mathrm{~min}$ ( $\operatorname{step} \mathrm{V}$ ). The results of a representative control experiment, where a cytosol-like $\left(\mathrm{K}^{+}\right.$-rich) solution was used during the dialysis, are shown in Fig. 7 B (the Roman numerals refer to the corresponding steps in the protocol schematic of Fig. 7 A). Comparable experiments using either an $\mathrm{NMDG}^{+}$-based dialysis solution or $\mathrm{NMDG}^{+}$-based solution without the cytosolic dialysis step are illustrated in Fig. S3.

To evaluate the extent of re-acidification observed after lysosomal cation dialysis followed by removal of GPN, we constructed histograms of pooled lysosome $\mathrm{pH}$ determinations from multiple experiments (Fig. $7 \mathrm{C}$ ). When $\mathrm{K}^{+}$was resealed into the lysosomes, mimicking the conditions prevailing physiologically, the lysosomes acidified back to $\mathrm{pH}=5.44$ (median of 1,349 determinations), approaching the normal resting value. In stark contrast, lysosomes dialyzed with $\mathrm{Na}^{+}$- and $\mathrm{K}^{+}$-free solutions, containing either Tris or $\mathrm{NMDG}^{+}$, were unable to re-acidify (median re-acidification $\mathrm{pH}>6.5$ and 6.26 for Tris and $\mathrm{NMDG}^{+}$, respectively). The inability to acidify was not the result of untoward deleterious effects of the organic cations because when the ionsubstitution protocol was performed in the absence of bzATP, and thus without actually dialyzing the cytosol and lysosome lumen, 
A
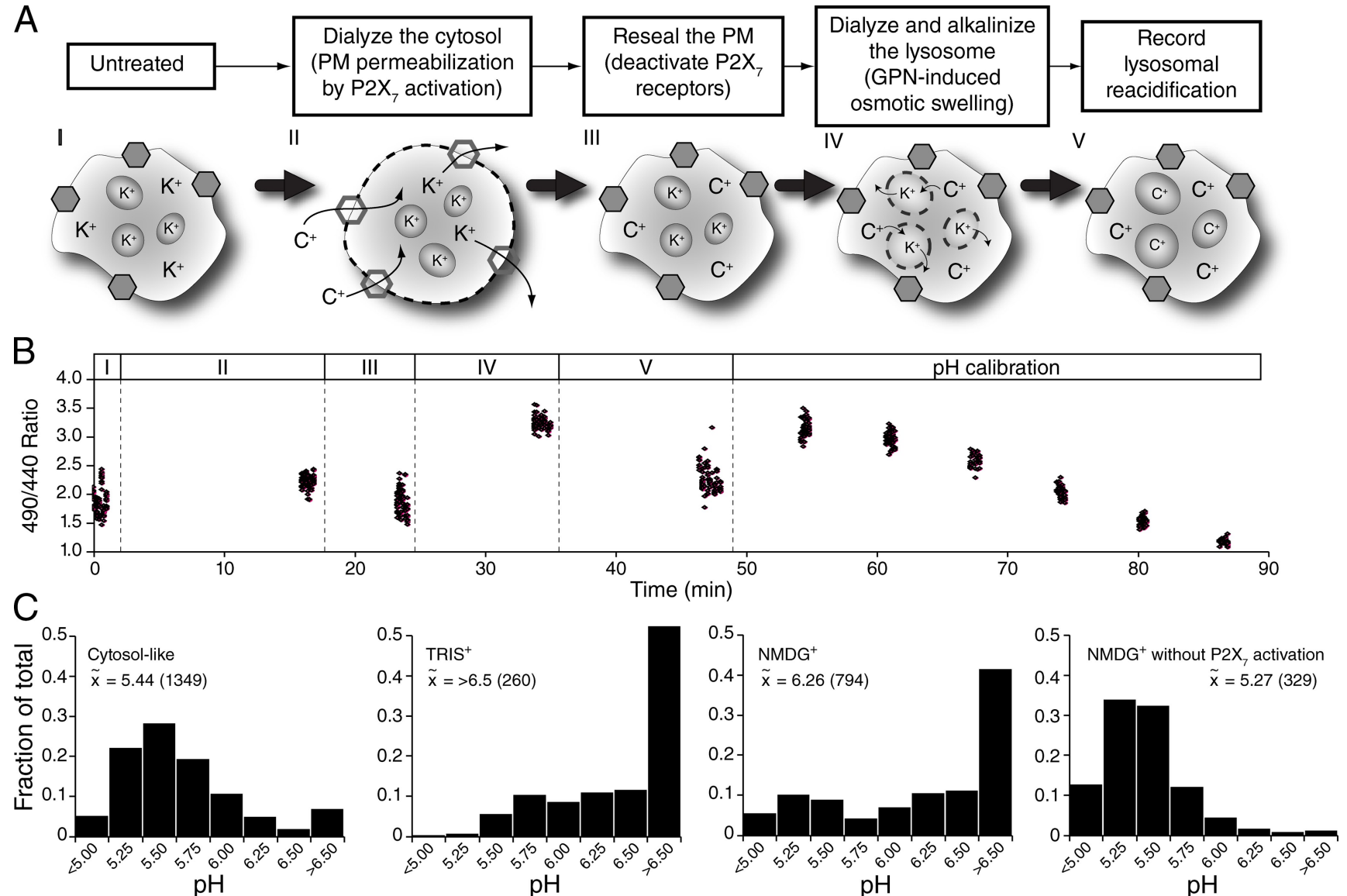

Figure 7. Role of lysosomal cations in lysosome re-acidification after GPN-induced alkalinization. (A) Schematic of the experimental protocol used to dialyze and transiently alkalinize lysosomes. After baseline $\mathrm{pH}$ measurements in RAW macrophages (step I), the cytosol was dialyzed by selectively permeabilizing the plasma membrane through the activation of resident P2X receptors in the presence of cation substitution buffers (step II). Removal of the P2X agonists and the addition of divalent cations resealed the plasma membrane (step III). The lysosomes were then dialyzed and alkalinized by GPN-induced osmotic swelling (step IV). The lysosomes were next allowed to re-acidify after removal of GPN (step V). An in situ calibration was performed at the end of each experiment (not illustrated). (B) Determinations of fluorescence ratio (proportional to $\mathrm{pH}$ ) of a representative control experiment where cells were dialyzed with a cytosol-like solution. Each data point represents the ratio data from an individual region of interest. The steps indicated by Roman numerals refer to the protocol schematic of panel A. (C) Histograms of pooled lysosome pH determinations after recovery from the GPN treatment (step $V$ of the illustrated protocol). The median $\mathrm{pH}$ of the lysosomes after the re-acidification period is given in the figure along with the total number of lysosomes used to compile the histograms. From left to right: cells dialyzed in cytosol-like ( $\mathrm{K}^{+}$-rich), Tris-substituted, or NMDG ${ }^{+}$-substituted medium. The rightmost histogram shows cells that were incubated with NMDG+-substituted medium but were not permeabilized. The histograms show collated data from nine, three, six, and two separate experiments, respectively.

normal lysosomal re-acidification was observed (median $\mathrm{pH}=$ 5.27; Fig. 7 C). When choline was used for dialysis, an intermediate level of re-acidification was observed (Fig. S3, D and E). Together, these observations indicate that, despite the presence of cytosolic $\mathrm{Cl}^{-}$, small inorganic cations are required for proper acidification, suggesting that in lysosomes a cation counterflux can neutralize the electrogenicity of the V-ATPase.

A second, independent approach was used to validate the existence of a cation conductance in the lysosomal membrane. Conductive permeability was assessed by measuring the rate of dissipation of the lysosomal acidification upon treatment with FCCP. Because this protonophore is rheogenic, a counter-ion is required to support measurable net outward movement of $\mathrm{H}^{+}$from the lysosomes (Fig. 8 B). We determined the rate of alkalinization induced by FCCP after dialysis of the cytosol with solutions containing $\mathrm{K}^{+}$, the predominant cytosolic cation, or $\mathrm{NMDG}^{+}$, a large poorly permeant substituent (see Fig. $8 \mathrm{~A}$ for the experimental protocol). To gain insight into the identity of the monovalent cationic counter-ion(s) that can support proton flux, we also compared $\mathrm{Na}^{+}$, the predominant extracellular cation, with $\mathrm{K}^{+}$. In the presence of cytosolic $\mathrm{K}^{+}$the lysosomes alkalinized rapidly, whereas the initial rate of alkalinization was considerably slower when using $\mathrm{NMDG}^{+}(\mathrm{P}<0.05$; Fig. 8, B and $\mathrm{C}) . \mathrm{Na}^{+}$, on the other hand, was able to sustain an alkalinization rate comparable to that of $\mathrm{K}^{+}(\mathrm{P}>0.05$; Fig. 8, B and $\mathrm{C})$. The above findings imply that counter-ion permeability can limit the flow of $\mathrm{H}^{+}$through the protonophore and, importantly, confirm the existence of sizable $\mathrm{K}^{+}$and $\mathrm{Na}^{+}$conductances in the lysosomal membrane.

\section{Discussion}

By developing new protocols to reversibly permeabilize the plasmalemma and the lysosomal membrane we were able to separately dialyze the cytosol and the lysosomal lumen to analyze the ionic dependence of acidification in situ. The primary finding of this study is that lysosomal luminal cations 

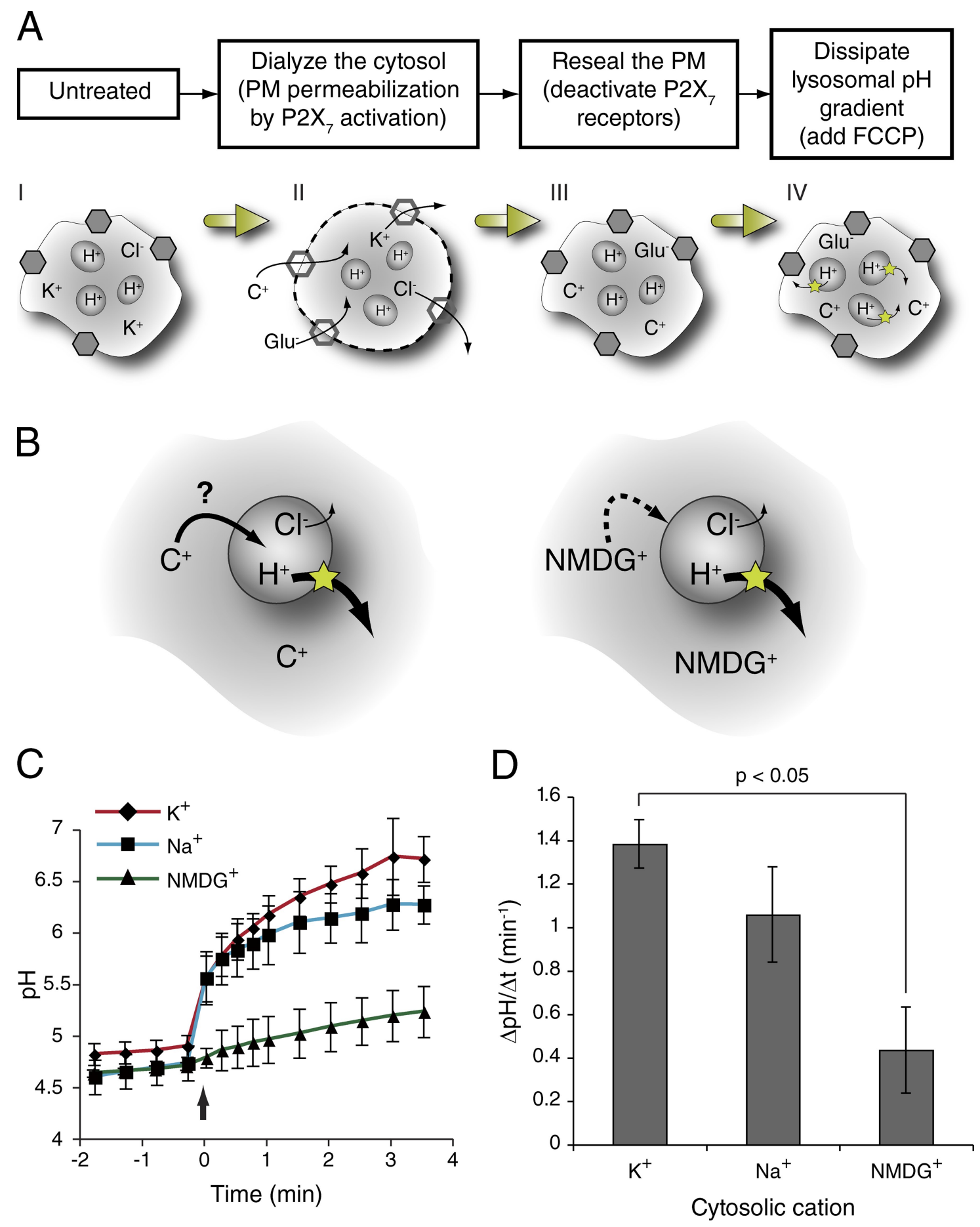

Figure 8. Cytosolic cations support protonophore-induced lysosome alkalinization. (A) Schematic representation of the experimental protocol used to dialyze and alkalinize the lysosomes. After baseline $\mathrm{pH}$ measurements (step I), the cytosol was dialyzed by selectively permeabilizing the plasma membrane through activation of $\mathrm{P} 2 \mathrm{X}_{7}$ receptors in the presence of suitable buffers (step II). Removal of the $\mathrm{P} 2 \mathrm{X}_{7}$ agonists and the addition of divalent cations resealed the plasma membrane (step III). The lysosomes were then alkalinized by FCCP treatment (step IV). (B) Proton efflux from lysosomes requires either the parallel efflux of an anion or the influx of a cation. When protonophore (green star) is added, counter-ions must move across the lysosome membrane to prevent membrane potential buildup. Before addition of the protonophore, the cytosol was dialyzed in the presence of either $\mathrm{K}^{+}, \mathrm{Na}^{+}$(left) or $\mathrm{NMDG}^{+}$(right), a relatively impermeant cation. If a $\mathrm{K}^{+}$and/or $\mathrm{Na}^{+}$conductance exists, $\mathrm{NMDG}^{+}$will impair lysosome alkalinization, as it cannot be effectively transported into the lysosome lumen to dissipate the voltage. (C) Lysosome alkalinization in cells dialyzed with $\mathrm{K}^{+}$-rich (diamond), $\mathrm{Na}^{+}$-rich (squares), or $\mathrm{NMDG}^{+}$-rich solution (triangles). The time course of the change in $\mathrm{pH}$ after FCCP addition (arrow) is illustrated for representative experiments (means \pm SD). (D) The rate of $\mathrm{pH}$ dissipation over the first minute of FCCP-induced alkalinization for the three different cations.

can function as the counter-ions that enable lysosomal acidification by dissipating the membrane potential generated by the V-ATPase.
We found that, in otherwise untreated cells, the lysosomes were able to re-acidify fully after a transient protonophoreinduced alkalinization. Strikingly, the re-acidification was equally 
rapid and complete in cells where the cytosolic $\mathrm{Cl}^{-}$had been replaced with large organic anions such as gluconate and $\mathrm{MeSO}_{3}{ }^{-}$. Because these are negligibly permeable through most $\mathrm{Cl}^{-}$conductive pathways, including CLC chloride transporters and CFTR channels (Linsdell et al., 1997; Jentsch, 2008), we inferred that cytosolic anions are not absolutely essential for lysosome acidification. That cytosolic anions are dispensable was corroborated by measuring re-acidification in a cell-free preparation of isolated lysosomes in the absence of $\mathrm{Cl}^{-}$(Fig. 4). In both types of experiments, protonophores were used to dissipate the preexisting $\mathrm{pH}$ gradients, and this was followed by protonophore removal to reinitiate acidification. It is most likely that removal of the protonophore was not complete, which would result in underestimation of the rate of the V-ATPase due to futile cycles of proton pumping and leakage. Nevertheless, the measured acidification required net transport of protons with concomitant transport of a counter-ion other than chloride. This conclusion differs from those reached by others, but differences in the experimental design may account for the apparent discrepancies. Moreover, our data do not negate the existence of a parallel anion conductance. Indeed, we were able to confirm that, when cations are removed from the lumen of the lysosomes, $\mathrm{a} \mathrm{Cl}^{-}$dependent acidification is revealed (Fig. 4 C). Thus, lysosomal proton pumping can be supported by either an influx of $\mathrm{Cl}^{-}$or by the exit of luminal cations.

In an important study, acidification was studied in situ in macrophages and found to require anion transport via CFTR (Di et al., 2006). More recently, defective lysosomal acidification was also invoked as the mechanism underlying ceramide accumulation in CF lysosomes (Teichgräber et al., 2008). Yet the conclusions reached by Di et al. (2006) regarding the role of CFTR in lysosomes are not universally accepted. The observations of Haggie and Verkman (2007) and Barriere et al. (2009) failed to confirm the involvement of CFTR in acidification, as did ours. We found that pharmacological inhibition of CFTR channel activity did not perturb lysosome $\mathrm{pH}$ and that primary alveolar macrophages lacking functional CFTR had no measurable impairment in lysosomal acidification. In fact, it is not clear whether CFTR would be operational at the extremely acidic $\mathrm{pH}$ that prevails in the lysosomal lumen. In BHK cells stably expressing CFTR on their plasma membrane the anion flux induced by elevation of cAMP was acutely inhibited when the $\mathrm{pH}$ of the bathing medium, topologically equivalent to the lysosome lumen, was reduced to 4.5 to mimic the lysosomal $\mathrm{pH}$ (Fig. S4). Taken together, the available data do not convincingly support a role for CFTR in lysosomal counter-ion conductance and defects in lysosomal acidification cannot fully explain the impaired microbicidal capacity in $\mathrm{CF}$.

Similarly, the $\mathrm{Cl}^{-} / \mathrm{H}^{+}$antiporter $\mathrm{ClC}-7$ has also been implicated as the counter-ion conductance in lysosomal acidification (Kornak et al., 2001; Graves et al., 2008). As proposed for other family members, uptake of $\mathrm{Cl}^{-}$via $\mathrm{ClC}-7$ could in principle serve as a neutralizing counter-ion to $\mathrm{H}^{+}$pumping, though the process would be inefficient (three $\mathrm{H}^{+}$pumped for every two accumulated if the stoichiometry of exchange is 2:1). However, lysosomal $\mathrm{pH}$ appears to be normal in macrophages from mice lacking ClC-7 (Fig. 2), as described previously for other cells
(Kornak et al., 2001; Kasper et al., 2005; Lange et al., 2006), implying that alternative counter-ion pathways exist in lysosomes. The experiments of Graves et al. (2008), which assigned to ClC-7 an essential role in lysosomal acidification, suffer from apparent methodological limitations that may explain the discrepancy with our results and those of Kasper et al. (2005) and Lange et al. (2006). In brief, Graves et al. (2008) used an acidotropic dye, LysoTracker, to estimate lysosomal pH. Accumulation of LysoTracker is an indirect and qualitative assay of $\mathrm{pH}$, which is affected by the number and size of acidic vesicles, parameters that were not determined by Graves et al. (2008). In addition, their evidence for a role for $\mathrm{ClC}-7$ in lysosome $\mathrm{pH}$ regulation relied on incomplete knockdown of the antiporter using a single siRNA. The interpretation of their data are further complicated by the disconcerting fact that their control siRNA treatment significantly increased LysoTracker fluorescence, even though it decreased $\mathrm{ClC}-7$ expression to some extent. Thus, rather than having no effect, the control treatment seemed to acidify or enlarge lysosomes. Considering these shortcomings, the results obtained with ratiometric fluorescence measurements in $\mathrm{Clcn} 7^{-1-}$ cells appear more reliable. Whether in knock-out or knock-down cells other vesicular $\mathrm{ClC}$ proteins can partially substitute for ClC-7 remains to be determined.

That lysosomes could acidify in the absence of permeable anions prompted us to consider whether lysosomal cations were capable of sustaining proton translocation by the V-ATPase. Because, to the best of our knowledge, the free concentration of inorganic cations in lysosomes had not been reported, the presence of potential luminal counter-ions had to be validated first. Our null-point determinations of $\mathrm{Na}^{+}$and $\mathrm{K}^{+}$activity indicated that inorganic cations are sufficiently abundant to sustain the acidification of lysosomes. It must be borne in mind that, in addition, inorganic cations taken up by fluid-phase endocytosis are delivered continuously to lysosomes, providing a continued source of potential counter-ions. More importantly, ion replacement experiments demonstrated that monovalent inorganic cations support the acidification process. This conclusion is not unprecedented; some in vitro studies had suggested that $\mathrm{K}^{+}$plays a more prominent role in facilitating lysosome acidification than does $\mathrm{Cl}^{-}$(Moriyama, 1988; Van Dyke, 1993). It is noteworthy also that lysosomes store significant amounts of $\mathrm{Ca}^{2+}$ (Haller et al., 1996a; Christensen et al., 2002) and this divalent cation could in principle also contribute to neutralize $\mathrm{H}^{+}$entry. However, we have thus far failed to confirm the participation of calcium: omission of calcium from the resealing solution in experiments like those in Fig. 3 had no discernible effect on the rate of re-acidification, and elevation of cytosolic calcium by treatment of cells with thapsigargin had no effect on lysosomal $\mathrm{pH}$ (Fig. S5).

It is interesting to speculate why lysosomes may use cations in addition to or instead of anions as counter-ions for acidification. Although anion influx and cation efflux would equally neutralize the charge accrued by proton translocation, the osmotic consequences of these processes are diametrically opposed. The uptake of an anion in parallel with each $\mathrm{H}^{+}$results in a net osmotic gain. The osmotic implications of counter-ion transport are best appreciated when considering that the intrinsic 
buffering power of lysosomes is comparatively high $(61.5 \pm$ $2.3 \mathrm{mM} / \mathrm{pH}$ at steady state in macrophages), likely due to their high protein content. Using the empirically measured intrinsic lysosomal buffering power, integrated over the $\mathrm{pH} 4.5-6.5$ range (Fig. S5 D), full acidification of the lysosome would require the parallel transport of $\geq 108 \mathrm{mmol}$ of counter-ions per liter of lysosomal volume. This gain in anionic osmolytes would cause considerable swelling and possibly lysis of the lysosomes, which are water permeable and susceptible to osmotically induced rupture, as revealed by the experiments using GPN. The ensuing collapse of the $\mathrm{pH}$ gradient and the release of degradative enzymes would obviously have a detrimental effect on the cell. By contrast, use of cations as counter-ions during acidification would guard against volume expansion. Instead, because incoming protons are largely scavenged by the luminal buffer, the loss of cations would result in lysosomal shrinking. By combining the use of cations and anions as counter-ions to protons, the lysosomes may be able to maintain their osmolarity and volume during the course of acidification.

To our knowledge, few specific cation channels or electrogenic transporters have been shown conclusively to function in the lysosomal membrane. Proteomic approaches are beginning to probe the protein landscape of the lysosomal membrane (Schröder et al., 2007) and, as more extensive lists are developed and consolidated, candidate conductive pathways will be identified. Their ability to function in the unusual environment of the lysosome and their role in lysosome acidification must then be tested.

\section{Materials and methods}

\section{Materials}

CFTR INH-1 -172 was purchased from EMD. Sulforhodamine 101, LysoTracker Red, Oregon Green 514-dextran, fluorescein-dextran, and rhodamine Bdextran were from Invitrogen. All dextrans were of 10,000 MW. Unless specified otherwise, all other reagents were from Sigma-Aldrich. Phosphate-

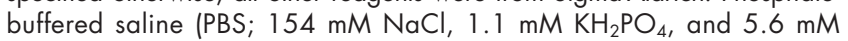
$\mathrm{Na}_{2} \mathrm{HPO}_{4}$ ) was purchased from Wisent.

\section{Cell lines and tissue culture}

RAW264.7 (number TIB-71) and 7774 (number TIB-67) murine macrophage cell lines were obtained from the American Type Culture Collection (Rockville, MD) and grown at $37^{\circ} \mathrm{C}$ under $5 \% \mathrm{CO}_{2}$ in DME supplemented with $5 \%$ fetal bovine serum (FBS; Wisent).

Bi-transgenic cftr-null mutant $\left(\mathrm{cftr}^{-}{ }^{-}\right)$mice, expressing human CFTR in the gut under the control of the rat fatty acid-binding protein (FABP) pro-

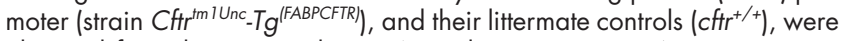
obtained from the Cystic Fibrosis Animal Core at Case Western Reserve University (Cleveland, OH). RT-PCR determinations using the primers 5'-TAAACCTACCAAGTCAACCA-3' forward, 5'-AATTCCATGAGCAAATGTC-3' reverse, failed to detect expression of the human transgene in the alveolar macrophages, whereas expression was clearly detectable in parallel samples of human airway epithelial cells (not illustrated). The Clcn $7^{-1-}$ mice, on a C57BL/6-129SV mixed background, as well as the murine adult fibroblasts, were described previously (Kornak et al., 2001). All animal protocols were approved by the animal care committee of the Hospital for Sick Children or the competent authorities of the city-state of Berlin.

To isolate alveolar macrophages, the mice were sacrificed and bronchoalveolar lavage performed. For each lavage, $1 \mathrm{ml}$ of cold PBS supplemented with $1 \mathrm{mM} \mathrm{CaCl} 2$ and $1 \mathrm{mM} \mathrm{MgCl}$ was instilled into the lungs by tracheal cannulation. The lavage was repeated three times to collect between 2 and $3 \mathrm{ml}$ of fluid. The collected cells from each mouse were cultured on glass coverslips at $37^{\circ} \mathrm{C}$ under $5 \% \mathrm{CO}_{2}$ in RPMI 1640 medium supplemented with $10 \% \mathrm{FBS}$ and a penicillin, streptomycin, and amphotericin B cocktail. Alveolar macrophages were used within $3 \mathrm{~d}$ of harvesting.

\section{Immunofluorescence microscopy}

For immunostaining, macrophages were fixed with 4\% PFA in PBS for $15 \mathrm{~min}$, incubated with $30 \mathrm{mM}$ glycine in PBS for $5 \mathrm{~min}$ and permeabilized with $0.05 \%$ saponin in PBS for $10 \mathrm{~min}$. Both primary and Alexa Fluor-coupled secondary (Invitrogen) antibodies were applied in PBS/0.05\% saponin supplemented with $3 \%$ BSA. Primary antibodies used were rat anti-mLamp 1 (BD), rat anti-mF4/80 (Cedarlane), and rabbit anti-ClC-7 (Kornak et al., 2001). Images were acquired with a laser-scanning confocal microscope (model LSM510; Carl Zeiss, Inc.) equipped with a 63x 1.4 NA oil-immersion lens using the ZEN imaging software (Carl Zeiss, Inc.). Images were further processed using Photoshop (Adobe).

\section{Lysosomal pH measurements}

Lysosomal $\mathrm{pH}$ measurements were performed by ratiometric fluorescence imaging of a pH-sensitive fluorophore specifically targeted to the compartment of interest using a standard pulse-chase protocol. Cultured cells were plated on glass coverslips and grown overnight in the presence of $500 \mu \mathrm{g} / \mathrm{ml}$ of Oregon Green 514-conjugated dextran. The cells were then washed and the dextran chased to the lysosome by incubating the cells at $37^{\circ} \mathrm{C}$ for $1 \mathrm{~h}$ in the presence of serum followed by $1 \mathrm{~h}$ in serum-free medium before imaging. Where indicated, cells were incubated with the indicated pharmacological agent during the hour in serum-free medium and then maintained in its presence for the duration of the experiment.

For imaging, coverslips were placed in a Leiden chamber maintained at $37^{\circ} \mathrm{C}$ and mounted on the stage of a microscope (model DM IRB; Leica). $\mathrm{pH}$ was measured by fluorescence ratiometric imaging using a filter wheel (Sutter Instrument Co.) to rapidly alternate between excitation filters. The cells were excited by light from an XFO X-Cite 120 lamp (XFO Life Sciences Group) transmitted alternately through $485 \pm 10 \mathrm{~nm}$ and $438 \pm 12 \mathrm{~nm}$ excitation filters and directed to the sample using a 505 -nm dichroic mirror. The emitted light was filtered with a $535 \pm 20 \mathrm{~nm}$ filter before being captured by a CCD camera (Cascade II; Photometrics). The filter wheel and camera were under the control of Metafluor software (MDS Analytical Technologies).

At the end of each experiment, an in situ calibration was performed. The cells were sequentially bathed in isotonic $\mathrm{K}^{+}$solutions $1145 \mathrm{mM} \mathrm{KCl}$, $10 \mathrm{mM}$ glucose, $1 \mathrm{mM} \mathrm{MgCl}$, and $20 \mathrm{mM}$ of either Hepes, MES, or acetate) buffered to $\mathrm{pH}$ ranging from 4.0 to 6.5 and containing $10 \mu \mathrm{g} / \mathrm{ml}$ of nigericin. Images were acquired $5 \mathrm{~min}$ after the addition of each solution to ensure equilibration of $\mathrm{pH}$ across compartments. The resulting fluorescence intensity ratio $(490 \mathrm{~nm} / 440 \mathrm{~nm})$ data as a function of $\mathrm{pH}$ were fit to a Boltzmann sigmoid and used to interpolate $\mathrm{pH}$ values from the experimental ratio data. By bathing the cells in $145 \mathrm{mM} \mathrm{KCl}$, the $\mathrm{K}^{+}$concentration gradient between the medium and the cytosol is virtually eliminated and the ionophore drives the cytosolic $\mathrm{pH}$ to that of the bathing medium. Nigericin also inserts into and functions within the lysosomal membrane. To fully equilibrate the lysosomal pH with that of the cytosol (and thus the bathing medium), we assume that there is a negligible $\mathrm{K}^{+}$concentration gradient across the lysosome membrane. Based on our null-point titration $\mathrm{K}^{+}$ determinations (Fig. 5) at steady state, there is approximately a threefold concentration difference. Were there no buffering power in the lysosome, this gradient would affect the $\mathrm{pH}$ measurement by $\sim 0.5(\log 3) \mathrm{pH}$ units. However, this error is mitigated by the lysosomal buffering power measured at $60-80 \mathrm{mM}$ in the $\mathrm{pH} 4.5-5.5$ range, which decreases the discrepancy to $\leq 0.13 \mathrm{pH}$ units, and by the existence of $\mathrm{K}^{+}$permeation pathways within the lysosomal membrane that promote equilibration between the lysosomal and cytosolic $\mathrm{K}^{+}$

The intrinsic lysosomal buffering power was determined by measuring the change in $\mathrm{pH}$ induced by graded pulses of weak electrolytes and calculated as described by Roos and Boron (1981). To estimate the buffering power as a function of $\mathrm{pH}$, the V-ATPase was inhibited by addition of $500 \mathrm{nM}$ CcA to slowly dissipate the luminal acidification. When the desired $\mathrm{pH}$ was attained, $\mathrm{NH}_{4} \mathrm{Cl}$ was added to the bathing medium and the magnitude of the sudden alkalinization was recorded. In this manner, we calculated the buffering power over $0.5 \mathrm{pH}$ unit intervals in the range of $\mathrm{pH}$ 4.5-6.5.

\section{Lysosome $\mathrm{pH}$ measurements in $\mathrm{Clcn}^{-/-}$mice}

Alveolar macrophages from ClC-7 knockout mice (Kornak et al., 2001) $3.5-5 \mathrm{wk}$ of age were harvested as above. The cells were plated on glassbottom live-cell dishes (MatTek) and $\mathrm{pH}$ measurements were performed after $2 \mathrm{~d}$. Lysosomes were loaded with $0.5 \mathrm{mg} / \mathrm{ml}$ Oregon Green 488-dextran (Invitrogen) in RPMI supplemented with 10\% FBS for at least $2 \mathrm{~h}$ followed by a 2 -h chase. In experiments investigating the effect of CFTR $\mathrm{INH}^{-172}$, the drug $(10 \mu \mathrm{M})$ was added to the medium $1 \mathrm{~h}$ before measurements. Images were acquired at $37^{\circ} \mathrm{C}$ using a microscope (Axiovert 200; Carl Zeiss, Inc.) 
equipped with a $100 \times 1.30 \mathrm{NA}$ oil-immersion lens, and with excitation at 440 and $488 \mathrm{~nm}$ delivered by a Polychrom II monochromator system (TILL Photonics). The emitted light was selected with a $535 \pm 20 \mathrm{~nm}$ filter and captured with a Sensicam CCD camera. For each animal, at least 10 different cells with at least 10 single lysosomes each were measured in $150 \mathrm{mM}$ $\mathrm{NaCl}, 1 \mathrm{mM} \mathrm{MgCl}, 2 \mathrm{mM} \mathrm{CaCl}, 10 \mathrm{mM}$ glucose, and $10 \mathrm{mM}$ Hepes, $\mathrm{pH}$ 7.4. Calibration was as above, but using both nigericin and monensin (10 $\mu \mathrm{M}$ each). Image acquisition and analysis were performed using TILLvision software (TILL Photonics). Data were exported to Excel (Microsoft) for further analysis and display.

\section{lon substitution and re-acidification protocols}

Lysosomes in RAW macrophages were loaded with Oregon Green 514 dextran and baseline $\mathrm{pH}$ recorded. The cytosol was subsequently dialyzed by incubating the cells in a dialysis medium containing $50 \mathrm{mM} \mathrm{KCl}, 90 \mathrm{mM}$ K gluconate, $20 \mathrm{mM}$ Hepes, $10 \mathrm{mM}$ glucose, $1 \mathrm{mM}$ EDTA, $1 \mathrm{mg} / \mathrm{ml}$ dextran (MW 1,500), $2.5 \mathrm{mM} \mathrm{Na} \mathrm{Na}_{2}$ ATP, and $100 \mu \mathrm{M}$ bzATP to activate plasmalemmal $\mathrm{P}_{2} \mathrm{X}_{7}$ receptors. Where specified, $\mathrm{Cl}^{-}$was isoosmotically replaced with either gluconate or $\mathrm{MeSO}_{3}{ }^{-}$. In all cases, the dialysis medium also contained $500 \mathrm{nM} \mathrm{FCCP} \mathrm{to} \mathrm{alkalinize} \mathrm{the} \mathrm{lysosomes.} \mathrm{After} 15 \mathrm{~min}$ of cytosol dialysis and lysosome alkalinization, re-acidification was initiated by washing the cells threefold with dialysis buffer supplemented with $3 \mathrm{mM} \mathrm{MgCl}$ and $1 \%$ albumin but without $\mathrm{P} 2 \mathrm{X}_{7}$ agonists and protonophore. The inclusion of $2 \mathrm{mM} \mathrm{CaCl}_{2}$ in the re-acidification medium did not impact on the rate or extent of lysosome re-acidification (Fig. S5 A). An in situ calibration concluded each experiment. A single field was monitored throughout the protocol.

A derivative of the above protocol was used to examine the role of lysosomal cations in lysosomal re-acidification. After baseline lysosome $\mathrm{pH}$ measurements in the RAW cells, the cytosol was dialyzed by incubation with a $\mathrm{P} 2 \mathrm{X}_{7}$ activation solution containing $90 \mathrm{mM} \mathrm{K}$ gluconate, $50 \mathrm{mM}$ $\mathrm{KCl}, 20 \mathrm{mM}$ Hepes, $10 \mathrm{mM}$ glucose, $1 \mathrm{mM}$ EDTA, $1 \mathrm{mg} / \mathrm{ml}$ dextran (MW

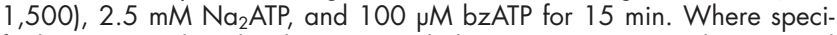
fied, $\mathrm{K}^{+}$was replaced with $\mathrm{NMDG}^{+}$, choline, or Tris; $50 \mathrm{mM} \mathrm{Cl}^{-}$was used throughout to approximate cytosolic $\mathrm{Cl}^{-}$levels. For the remainder of the experiment, the cells were maintained in a deactivation solution similar to the dialysis medium but without the $\mathrm{P} 2 \mathrm{X}_{7}$ agonists and supplemented with $1 \mathrm{mM} \mathrm{CaCl} 2$ and $1 \mathrm{mM} \mathrm{MgCl}$. The cells were allowed $5 \mathrm{~min}$ to recover before initiating lysosomal dialysis and alkalinization through the addition of $200 \mu M$ GPN to the bathing medium. After $10 \mathrm{~min}$ the cells were washed to remove GPN and given a further $10 \mathrm{~min}$ to recover. The protocol concluded with an in situ calibration. At the end of each step of the protocol, images from 5 to 15 fields were acquired.

The role for cations as possible counter-ions for lysosome $\mathrm{H}^{+}$transport was also examined by measuring protonophore-induced alkalinization in the presence and absence of permeant cytosolic cations. The lysosomes of RAW macrophages were first loaded with Oregon Green 514-dextran by the pulse-chase protocol described above, followed by dialysis of the macrophage cytosol by incubation with a $\mathrm{P} 2 \mathrm{X}_{7}$ activation solution containing $140 \mathrm{mM} \mathrm{K}$ gluconate, $20 \mathrm{mM}$ Hepes, $10 \mathrm{mM}$ glucose, $1 \mathrm{mM}$ EDTA, $1 \mathrm{mg} / \mathrm{ml}$ dextran (MW 1,500), and $100 \mu \mathrm{M}$ bzATP for $15 \mathrm{~min}$. Where indicated, $\mathrm{K}^{+}$was replaced with an equivalent amount of $\mathrm{NMDG}^{+}$. The cells were then maintained in a deactivation solution similar to the dialysis medium but supplemented with $1 \mathrm{mM} \mathrm{MgCl}$ and devoid of $\mathrm{P}_{2} \mathrm{X}_{7}$ agonists. After 5 min of recovery, $1 \mu M$ FCCP was added to the bathing medium and the rate of lysosome alkalinization was monitored. A single field of cells was imaged throughout in each experiment.

\section{Re-acidification of isolated lysosomes}

The lysosomes of RAW macrophages were loaded with Oregon Greendextran using the pulse-chase protocol described above. The cells were washed with either a $\mathrm{Cl}^{-}$-containing $190 \mathrm{mM} \mathrm{K}$ gluconate, $50 \mathrm{mM} \mathrm{KCl}$, $1 \mathrm{mM}$ EGTA, $20 \mathrm{mM}$ Hepes, $50 \mathrm{mM}$ sucrose, and protease inhibitor cocktail, $\mathrm{pH} \mathrm{7.3)} \mathrm{or} \mathrm{Cl}^{-}$-free solution (as above except with all the chloride replaced with gluconate) before treatment with $1 \mu \mathrm{M}$ FCCP for $15 \mathrm{~min}$ in order to completely dissipate the lysosomal pH gradient. Without the ionophore the lysosomes remained acidic, precluding assessment of the rate of acidification. The FCCP-treated cells were scraped into $1.5 \mathrm{ml}$ of the appropriate buffer and homogenized in a Dounce homogenizer. To prevent lysosomal re-acidification during the course of fractionation, the cells and homogenate were maintained in the continued presence of FCCP at $4^{\circ} \mathrm{C}$ until the final wash of the isolated organelles. To remove nuclei and unbroken cells the homogenate was centrifuged at $10,000 \mathrm{rpm}$ for $15 \mathrm{~s}$. The endomembranes in the recovered supernatant were next sedimented by centrifugation at $13,200 \mathrm{rpm}$ at $4^{\circ} \mathrm{C}$ for $20 \mathrm{~min}$, and then resuspended in $1 \mathrm{ml}$ of the appropriate buffer prewarmed to $37^{\circ} \mathrm{C}$, without FCCP and supplemented with $1 \%$ albumin to scavenge remaining ionophore. The protocol duration was minimized to ensure that the isolated organelles maintained their structural integrity. Sedimentation experiments showed that, under these conditions, less than $2 \%$ of the fluorescence was extralysosomal at the time of the measurements.

The lysosome-enriched preparation was maintained at $37^{\circ} \mathrm{C}$ and its fluorescence monitored using a fluorescence spectrophotometer (model F-2500; Hitachi) by exciting the sample at $490 \pm 5 \mathrm{~nm}$ and recording the emitted light at $520 \pm 5 \mathrm{~nm}$. A baseline $\mathrm{pH}$ measurement was performed in every experiment; the average starting lysosomal pH was 6.7. After the baseline determination, $5 \mathrm{mM} \mathrm{Mg}$ leither as the $\mathrm{Cl}^{-}$or sulfate salt, as appropriate) and $5 \mathrm{mM}$ ATP was added to the suspension, while continually monitoring fluorescence. Where indicated, $500 \mathrm{nM} \mathrm{CcA}$ was added along with the ATP to the suspension. At the end of the acidification, nigericin $(10 \mu \mathrm{g} / \mathrm{ml})$ was added to the sample to alkalinize the suspended lysosomes and ensure that they maintained their integrity over the course of the experiment.

A similar protocol was used to demonstrate the presence of an electrogenic $\mathrm{Cl}^{-}$conductance in the lysosome membrane. To minimize the contribution of any cation conductance(s), we first depleted lysosomal cations by incubating the intact cells in an NMDG+-based medium $190 \mathrm{mM} \mathrm{NMDG}$ gluconate, $50 \mathrm{mM} \mathrm{NMDG} \mathrm{Cl}, 20 \mathrm{mM}$ Hepes, $10 \mathrm{mM}$ glucose, $1 \mathrm{mM} \mathrm{MgCl}$, and $1 \mathrm{mM} \mathrm{CaCl}$ ) for $1 \mathrm{~h}$ with frequent washes. The remainder of the experiment was similarly performed in solutions devoid of small, inorganic cations. The cells were then treated with FCCP for 15 min to ensure that the lysosome $\mathrm{pH}$ gradient was dissipated. Lysosomes, preloaded with FITC-dextran as above, were then harvested in a sucrose-based medium $(350 \mathrm{mM}$ sucrose, $1 \mathrm{mM}$ EGTA, $20 \mathrm{mM}$ Hepes, and protease inhibitor cocktail, pH 7.3). Where specified, this medium was supplemented with $50 \mathrm{mM}$ chloride (as the NMDG salt). In these instances the sucrose content was decreased accordingly to maintain osmolarity.

\section{Null-point titration determinations of lysosomal $\mathrm{K}^{+}$and $\mathrm{Na}^{+}$}

The ionophores used for the null-point titration experiments catalyze the stoichiometric and electroneutral exchange of protons for alkali cations. In the case of nigericin, which is highly selective for $\mathrm{K}^{+}$, no net movement of protons across the membrane-and thus no $\mathrm{pH}$ change-will be induced by addition of the ionophore when

$$
\frac{H_{l}}{H_{c}}=\frac{K_{l}}{K_{c}},
$$

where $\mathrm{H}_{1}$ is the lysosomal proton activity, $\mathrm{H}_{c}$ is the cytosolic proton activity, $K_{l}$ is the lysosomal potassium activity, and $K_{c}$ is the cytosolic potassium activity. From this "null-point" the lysosomal potassium activity can be calculated as

$$
K_{l}=K_{c} \times 10^{\left(p H_{c}-p H_{l}\right)} .
$$

Monensin prefers $\mathrm{Na}^{+}$, but significant transport of $\mathrm{K}^{+}$also occurs. In this case the null-point is defined by:

$$
\frac{H_{l}}{H_{c}}=\frac{N a_{l}^{+}\left(\frac{P_{K} K_{N a}}{P_{N a} K_{K}}\right) K_{l}}{N a_{c}+\left(\frac{P_{K} K_{N a}}{P_{N a} K_{K}}\right) K_{c}},
$$

where $\mathrm{H}_{1}, \mathrm{H}_{c}, \mathrm{~K}_{1}$, and $\mathrm{K}_{c}$ are as defined above, $\mathrm{Na}_{1}$ is the lysosomal sodium activity, $\mathrm{Na}_{\mathrm{c}}$ is the cytosolic sodium activity, $\mathrm{P}_{\mathrm{K}}$ and $\mathrm{P}_{\mathrm{Na}}$ are the potassiumand sodium-ionophore complex translocation rates, respectively, and $\kappa_{k}$ and $\mathrm{\kappa}_{\mathrm{Na}}$ are, respectively, the potassium and sodium dissociation rates from the ionophore.

From the above relationship we obtain

$$
N a_{l}=\left[N a_{c}+\frac{1}{p} K_{c}\right] \times 10^{\left(p H_{c}-p H_{l}\right)}-\frac{1}{p} K_{l}
$$

where

$$
\frac{1}{P}=\left(\frac{P_{K} K_{N a}}{P_{N a} K_{K}}\right) .
$$


Our calculations use a selectivity coefficient $P$ of 25 , in accordance with published estimates (Prabhananda and Kombrabail, 1992; Nachliel et al., 1996; Rochdi et al., 1996).

To carry out determinations of lysosomal $\mathrm{K}^{+}$by null-point titration, RAW264.7 cells were plated on glass coverslips and their lysosomes loaded with fluorescein-labeled dextran using the pulse-chase protocol described above. The cytosolic ion composition was manipulated by incubating the cells for $15 \mathrm{~min}$ in titration buffer $10 \mathrm{mM} \mathrm{NaCl}, 20 \mathrm{mM} \mathrm{KCl}, 20 \mathrm{mM}$ NMDG Cl, $90 \mathrm{mM}$ NMDG gluconate, $10 \mathrm{mM}$ glucose, $20 \mathrm{mM}$ MES, and $1 \mathrm{mg} / \mathrm{ml}$ of $1,500 \mathrm{MW}$ dextran, set to $\mathrm{pH} 6.5$ or 7.3 , as indicated, with $\mathrm{NaOH}$ ) containing $100 \mu \mathrm{M}$ bzATP and $2 \mathrm{mM} \mathrm{Na}{ }_{2}$ ATP to stimulate P2X receptors. The solution was replaced with titration buffer without the P2X agonists and containing various concentrations of trimethylamine (TMA) to alkalinize the lysosome, plus $1 \mu \mathrm{M} \mathrm{CcA}$ to inhibit the V-ATPase. After 2-4 min, nigericin $(10 \mu \mathrm{g} / \mathrm{ml})$ was added to the medium. An in situ calibration was performed at the end of each experiment. A single field was monitored by ratiometric imaging at every step of the protocol. $\mathrm{Na}^{+}$determinations were similar, except the titration buffer consisted of $10 \mathrm{mM} \mathrm{NaCl}, 40 \mathrm{mM}$ $\mathrm{KCl}, 10 \mathrm{mM} \mathrm{K}$ gluconate, 80 NMDG gluconate, $10 \mathrm{mM}$ glucose, $20 \mathrm{mM}$ MES, and $1 \mathrm{mg} / \mathrm{ml}$ of $1,500 \mathrm{MW}$ dextran, set to $\mathrm{pH} 6.5$ with Tris, and monensin $(20 \mu \mathrm{g} / \mathrm{ml})$ was used instead of nigericin.

\section{Colorimetric determination of intracellular $\mathrm{Cl}^{-}$}

The colorimetric chloride determination was adapted from Zall et al. (1956). Cells were either left untreated or had their cytosol dialyzed by incubation in a nitrate-based $\mathrm{P} 2 \mathrm{X}_{7}$ receptor activation solution $\left(140 \mathrm{KNO}_{3}, 20 \mathrm{mM}\right.$ Hepes, $10 \mathrm{mM}$ glucose, $1 \mathrm{mM}$ EDTA, $2.5 \mathrm{mM} \mathrm{Na} 2$ ATP, $100 \mu \mathrm{M} \mathrm{bzATP}$, and $1 \mathrm{mg} / \mathrm{ml}$ dextran) for $15 \mathrm{~min}$. They were subsequently washed thoroughly with cold $\mathrm{NaNO}_{3}$ medium $\left(130 \mathrm{mMNaNO}_{3}, 3 \mathrm{mM} \mathrm{KNO}_{3}, 1 \mathrm{Mg}\left(\mathrm{NO}_{3}\right)_{2}, 1 \mathrm{Ca}\left(\mathrm{NO}_{3}\right)_{2}\right.$, $10 \mathrm{mM}$ glucose, and $20 \mathrm{mM}$ Hepes, $\mathrm{pH} 7.4$ ), then lysed in $1 \mathrm{mM}$ nitric acid. After centrifugation, the supernatant was collected and mixed with an equal volume of the photometric determination solution (1 part $0.417 \%$ mercuric thiocyanate in methanol, 1 part $20.2 \%$ ferric nitrate solution, and 13 parts water). The ferric nitrate was made by dissolving $20.2 \mathrm{~g}$ of ferric nitrate in $31 \mathrm{ml}$ of $4 \mathrm{~N} \mathrm{HNO}_{3}$, which was brought to a final volume of $100 \mathrm{ml}$ with distilled water. The absorbance at $480 \mathrm{~nm}$ of the experimental samples and $\mathrm{Cl}^{-}$standards was determined using a VERSAmax microplate reader (MDS Analytical Technologies). In parallel experiments, cells were incubated in the nitrate-based, chloride-free medium for $1.5 \mathrm{~h}$ with frequent washes, and similarly prepared. The signal from these samples consists of nonexchangeable chloride and nonspecific background of the colorimetric reaction, which were subtracted from all experimental samples. Cell number and volume were determined in parallel using the Coulter-Channelyzer in order to calculate intracellular $\mathrm{Cl}^{-}$concentrations.

\section{Data analysis and statistics}

Measurements of lysosome re-acidification after protonophore-induced alkalinization were fit with a single exponential of the form $y=A$ * $\exp (-K x)+B$ to calculate the half-life of the $\mathrm{pH}$ decay $(\tau=0.69 / K)$ reported in Table I. Null-point titration data were fit using least-squares linear regression to determine the $x$-intercept.

Data are reported as representative traces or mean \pm SE for the indicated number of experiments. The statistical significance of differences between multiple groups was determined using analysis of variance (ANOVA) with Dunnett's multiple comparison test for pairwise comparisons with control data. P-values $<0.05$ were considered statistically significant. Statistical analyses were performed using either SAS or Prism 4 by GraphPad Software, Inc.

\section{Online supplemental material}

Fig. S1 shows the colocalization of ClC-7 with LAMP-1 in alveolar macrophages. Fig. S2 shows validation of the effectiveness of the cytosolic dialysis accomplished by activation of $\mathrm{P} 2 \mathrm{X}_{7}$ and a comparison of two independent null-point titrations of lysosomal $\mathrm{K}^{+}$content. Fig. S3 illustrates the occurrence of lysosome re-acidification after luminal cation dialysis. Fig. S4 shows that cAMP-dependent iodide efflux was readily detectable in CFTR-expressing BHK cells but not in their untransfected counterparts, and also illustrates the effect of extracellular acidification on CFTR function. Fig. S5 analyses the effect of calcium on lysosomal $\mathrm{pH}$ and shows the $\mathrm{pH}$ dependence of the lysosomal buffering power. Online supplemental material is available at http://www.jcb.org/cgi/content/full/jcb.20091 1083/DC1.

We thank Jonathan D. Plumb for technical help, Drs. Fiona Lovegrove and Eric Vachon for help with bronchoalveolar lavage, and Drs. Andras Kapus and David Bazett-Jones for useful discussions.
This work was supported by grant FRN4665 from the Canadian Institutes of Health Research (CIHR), the Canadian Cystic Fibrosis Foundation (CCFF), and the Heart and Stroke Foundation of Ontario to S. Grinstein and the Deutsche Forschungsgemeinschaft (Je 164/7) to T.J. Jentsch. B.E. Steinberg is the recipient of studentships from the Maclaughlin Centre for Molecular Medicine and the CIHR. K.K. Huynh holds a CIHR Canadian Graduate Scholarship. S. Grinstein is the current holder of the Pitblado Chair in Cell Biology.

Submitted: 16 November 2009

Accepted: 26 May 2010

\section{References}

Barriere, H., M. Bagdany, F. Bossard, T. Okiyoneda, G. Wojewodka, D. Gruenert, D. Radzioch, and G.L. Lukacs. 2009. Revisiting the role of cystic fibrosis transmembrane conductance regulator and counterion permeability in the pH regulation of endocytic organelles. Mol. Biol. Cell. 20:3125-3141. doi:10.1091/mbc.E09-01-0061

Berg, T.O., E. Strømhaug, T. Løvdal, O. Seglen, and T. Berg. 1994. Use of glycylL-phenylalanine 2-naphthylamide, a lysosome-disrupting cathepsin C substrate, to distinguish between lysosomes and prelysosomal endocytic vacuoles. Biochem. J. 300:229-236.

Christensen, K.A., J.T. Myers, and J.A. Swanson. 2002. pH-dependent regulation of lysosomal calcium in macrophages. J. Cell Sci. 115:599-607.

Di, A., M.E. Brown, L.V. Deriy, C. Li, F.L. Szeto, Y. Chen, P. Huang, J. Tong, A.P. Naren, V. Bindokas, et al. 2006. CFTR regulates phagosome acidification in macrophages and alters bactericidal activity. Nat. Cell Biol. 8:933-944. doi:10.1038/ncb1456

Forgac, M. 2007. Vacuolar ATPases: rotary proton pumps in physiology and pathophysiology. Nat. Rev. Mol. Cell Biol. 8:917-929. doi:10.1038/nrm2272

Graves, A.R., P.K. Curran, C.L. Smith, and J.A. Mindell. 2008. The Cl-/H+ antiporter $\mathrm{ClC}-7$ is the primary chloride permeation pathway in lysosomes. Nature. 453:788-792. doi:10.1038/nature06907

Günther, W., A. Lüchow, F. Cluzeaud, A. Vandewalle, and T.J. Jentsch. 1998. ClC-5, the chloride channel mutated in Dent's disease, colocalizes with the proton pump in endocytotically active kidney cells. Proc. Natl. Acad. Sci. USA. 95:8075-8080. doi:10.1073/pnas.95.14.8075

Günther, W., N. Piwon, and T.J. Jentsch. 2003. The ClC-5 chloride channel knock-out mouse - an animal model for Dent's disease. Pflïgers Arch. 445:456-462.

Haggie, P.M., and A.S. Verkman. 2007. Cystic fibrosis transmembrane conductance regulator-independent phagosomal acidification in macrophages. J. Biol. Chem. 282:31422-31428. doi:10.1074/jbc.M705296200

Haller, T., P. Dietl, P. Deetjen, and H. Völkl. 1996a. The lysosomal compartment as intracellular calcium store in MDCK cells: a possible involvement in InsP3-mediated Ca2+ release. Cell Calcium. 19:157-165. doi:10.1016/S0143-4160(96)90084-6

Haller, T., H. Völk1, P. Deetjen, and P. Dietl. 1996b. The lysosomal Ca2+ pool in MDCK cells can be released by ins(1,4,5)P3-dependent hormones or thapsigargin but does not activate store-operated $\mathrm{Ca} 2+$ entry. Biochem. J. 319:909-912.

Hara-Chikuma, M., Y. Wang, S.E. Guggino, W.B. Guggino, and A.S. Verkman. 2005a. Impaired acidification in early endosomes of ClC-5 deficient proximal tubule. Biochem. Biophys. Res. Commun. 329:941-946. doi:10 $.1016 /$ j.bbrc.2005.02.060

Hara-Chikuma, M., B. Yang, N.D. Sonawane, S. Sasaki, S. Uchida, and A.S. Verkman. 2005b. CIC-3 chloride channels facilitate endosomal acidification and chloride accumulation. J. Biol. Chem. 280:1241-1247. doi:10.1074/jbc.M407030200

Jadot, M., C. Colmant, S. Wattiaux-De Coninck, and R. Wattiaux. 1984. Intralysosomal hydrolysis of glycyl-L-phenylalanine 2-naphthylamide. Biochem. J. 219:965-970.

Jentsch, T.J. 2008. CLC chloride channels and transporters: from genes to protein structure, pathology and physiology. Crit. Rev. Biochem. Mol. Biol. 43:3-36. doi:10.1080/10409230701829110

Kasper, D., R. Planells-Cases, J.C. Fuhrmann, O. Scheel, O. Zeitz, K. Ruether, A. Schmitt, M. Poët, R. Steinfeld, M. Schweizer, et al. 2005. Loss of the chloride channel ClC-7 leads to lysosomal storage disease and neurodegeneration. EMBO J. 24:1079-1091. doi:10.1038/ sj.emboj. 7600576

Kornak, U., D. Kasper, M.R. Bösl, E. Kaiser, M. Schweizer, A. Schulz, W. Friedrich, G. Delling, and T.J. Jentsch. 2001. Loss of the ClC-7 chloride channel leads to osteopetrosis in mice and man. Cell. 104:205-215. doi:10.1016/S0092-8674(01)00206-9

Lamothe, J., and M.A. Valvano. 2008. Burkholderia cenocepacia-induced delay of acidification and phagolysosomal fusion in cystic fibrosis 
transmembrane conductance regulator (CFTR)-defective macrophages. Microbiology. 154:3825-3834. doi:10.1099/mic.0.2008/023200-0

Lange, P.F., L. Wartosch, T.J. Jentsch, and J.C. Fuhrmann. 2006. ClC-7 requires Ostm1 as a beta-subunit to support bone resorption and lysosomal function. Nature. 440:220-223. doi:10.1038/nature04535

Li, X., T. Wang, Z. Zhao, and S.A. Weinman. 2002. The ClC-3 chloride channel promotes acidification of lysosomes in CHO-K1 and Huh-7 cells. Am. J. Physiol. Cell Physiol. 282:C1483-C1491.

Linsdell, P., J.A. Tabcharani, J.M. Rommens, Y.X. Hou, X.B. Chang, L.C. Tsui, J.R. Riordan, and J.W. Hanrahan. 1997. Permeability of wildtype and mutant cystic fibrosis transmembrane conductance regulator chloride channels to polyatomic anions. J. Gen. Physiol. 110:355-364. doi:10.1085/jgp.110.4.355

Ma, T., J.R. Thiagarajah, H. Yang, N.D. Sonawane, C. Folli, L.J. Galietta, and A.S. Verkman. 2002. Thiazolidinone CFTR inhibitor identified by high-throughput screening blocks cholera toxin-induced intestinal fluid secretion. J. Clin. Invest. 110:1651-1658.

McGuinness, L., S.J. Bardo, and N.J. Emptage. 2007. The lysosome or lysosomerelated organelle may serve as a $\mathrm{Ca} 2+$ store in the boutons of hippocampal pyramidal cells. Neuropharmacology. 52:126-135. doi:10.1016/ j.neuropharm.2006.07.029

Mohammad-Panah, R., R. Harrison, S. Dhani, C. Ackerley, L.J. Huan, Y. Wang, and C.E. Bear. 2003. The chloride channel ClC-4 contributes to endosomal acidification and trafficking. J. Biol. Chem. 278:29267-29277. doi:10.1074/jbc.M304357200

Moriyama, Y. 1988. Potassium ion dependent proton efflux and depolarization from spleen lysosomes. Biochem. Biophys. Res. Commun. 156:211-216. doi:10.1016/S0006-291X(88)80826-X

Nachliel, E., Y. Finkelstein, and M. Gutman. 1996. The mechanism of monensinmediated cation exchange based on real time measurements. Biochim. Biophys. Acta. 1285:131-145. doi:10.1016/S0005-2736(96)00149-6

Pelegrin, P., and A. Surprenant. 2006. Pannexin-1 mediates large pore formation and interleukin-1beta release by the ATP-gated $\mathrm{P} 2 \mathrm{X} 7$ receptor. EMBO J. 25:5071-5082. doi:10.1038/sj.emboj.7601378

Pelegrin, P., C. Barroso-Gutierrez, and A. Surprenant. 2008. P2X7 receptor differentially couples to distinct release pathways for IL-1beta in mouse macrophage. J. Immunol. 180:7147-7157.

Perez, A., A.C. Issler, C.U. Cotton, T.J. Kelley, A.S. Verkman, and P.B. Davis. 2007. CFTR inhibition mimics the cystic fibrosis inflammatory profile. Am. J. Physiol. Lung Cell. Mol. Physiol. 292:L383-L395. doi:10.1152/ajplung.00403.2005

Pillay, C.S., E. Elliott, and C. Dennison. 2002. Endolysosomal proteolysis and its regulation. Biochem. J. 363:417-429. doi:10.1042/0264-6021:3630417

Piwon, N., W. Günther, M. Schwake, M.R. Bösl, and T.J. Jentsch. 2000. ClC-5 Cl- -channel disruption impairs endocytosis in a mouse model for Dent's disease. Nature. 408:369-373. doi:10.1038/35042597

Prabhananda, B.S., and M.H. Kombrabail. 1992. Monensin-mediated transports of $\mathrm{H}+, \mathrm{Na}+, \mathrm{K}+$ and $\mathrm{Li}+$ ions across vesicular membranes: T-jump studies. Biochim. Biophys. Acta. 1106:171-177. doi:10.1016/0005-2736(92)90236-F

Rochdi, M., A.M. Delort, J. Guyot, M. Sancelme, S. Gibot, J.G. Gourcy, G. Dauphin, C. Gumila, H. Vial, and G. Jeminet. 1996. Ionophore properties of monensin derivatives studied on human erythrocytes by $23 \mathrm{Na} \mathrm{NMR}$ and $\mathrm{K}+$ and $\mathrm{H}+$ potentiometry: relationship with antimicrobial and antimalarial activities. J. Med. Chem. 39:588-595. doi:10.1021/jm9505829

Roos, A., and W.F. Boron. 1981. Intracellular pH. Physiol. Rev. 61:296-434.

Schröder, B., C. Wrocklage, C. Pan, R. Jäger, B. Kösters, H. Schäfer, H.P. Elsässer, M. Mann, and A. Hasilik. 2007. Integral and associated lysosomal membrane proteins. Traffic. 8:1676-1686. doi:10.1111/j.16000854.2007.00643.x

Srinivas, S.P., A. Ong, L. Goon, L. Goon, and J.A. Bonanno. 2002. Lysosomal $\mathrm{Ca}(2+)$ stores in bovine corneal endothelium. Invest. Ophthalmol. Vis. Sci. 43:2341-2350.

Teichgräber, V., M. Ulrich, N. Endlich, J. Riethmüller, B. Wilker, C.C. De Oliveira-Munding, A.M. van Heeckeren, M.L. Barr, G. von Kürthy, K.W. Schmid, et al. 2008. Ceramide accumulation mediates inflammation, cell death and infection susceptibility in cystic fibrosis. Nat. Med. 14:382391. doi:10.1038/nm1748

Thiagarajah, J.R., Y. Song, P.M. Haggie, and A.S. Verkman. 2004. A small molecule CFTR inhibitor produces cystic fibrosis-like submucosal gland fluid secretions in normal airways. FASEB J. 18:875-877.

Van Dyke, R.W. 1993. Acidification of rat liver lysosomes: quantitation and comparison with endosomes. Am. J. Physiol. 265:C901-C917.

Zall, D.M., D. Fisher, and M.Q. Garner. 1956. Photometric determination of chlorides in water. Anal. Chem. 28:1665-1668. doi:10.1021/ac60119a009 